\title{
Gene expression alterations of human liver cancer cells following borax exposure
}

\author{
LUN WU $^{1,2}$, YING WEI $^{3}$, WEN-BO ZHOU ${ }^{2}$, YOU-SHUN ZHANG $^{2}$, QIN-HUA CHEN ${ }^{4}$, MING-XING LIU $^{5}$, \\ ZHENG-PENG ZHU ${ }^{6}$, JIAO ZHOU ${ }^{3}$, LI-HUA YANG ${ }^{7}$, HONG-MEI WANG $^{3}$, \\ GUANG-MIN WEI ${ }^{2}$, SHENG WANG ${ }^{3}$ and ZHI-GANG TANG ${ }^{1}$
}

\begin{abstract}
${ }^{1}$ Department of Pancreatic Surgery, Renmin Hospital of Wuhan University, Wuhan University, Wuhan, Hubei 430060; ${ }^{2}$ Liver Surgery Institute of The Experiment Center of Medicine, Department of Hepatobiliary Surgery, Dongfeng Hospital, Hubei University of Medicine; ${ }^{3}$ Liver Surgery Institute of The Experiment Center of Medicine, Dongfeng Hospital, Hubei University of Medicine; ${ }^{4}$ Hubei Key Laboratory of Wudang Local Chinese Medicine Research, Experiment Center of Medicine, Hubei University of Medicine, Shiyan, Hubei 442001; ${ }^{5}$ Department of Pediatrics, YunXi Health for Women And Children, Children's Hospital, Maternal \& Child Care and Family Planning Service Centre, Shiyan, Hubei 442600; ${ }^{6}$ Department of Pathology, Dongfeng Hospital, Hubei University of Medicine; ${ }^{7}$ Subject Construction Office, Dongfeng Hospital, Hubei University of Medicine, Shiyan, Hubei 442001, P.R. China
\end{abstract}

Received October 20, 2018; Accepted May 20, 2019

DOI: $10.3892 /$ or.2019.7169

\begin{abstract}
Borax is a boron compound that is becoming widely recognized for its biological effects, including lipid peroxidation, cytotoxicity, genotoxicity, antioxidant activity and potential therapeutic benefits. However, it remains unknown whether exposure of human liver cancer (HepG2) cells to borax affects the gene expression of these cells. HepG2 cells were treated with $4 \mathrm{mM}$ borax for either 2 or $24 \mathrm{~h}$. Gene expression analysis was performed using Affymetrix GeneChip Human Gene 2.0 ST Arrays, which was followed by gene ontology analysis and pathway analysis. The clustering result was validated using reverse transcription-quantitative polymerase chain reaction. A cell proliferation assay was performed using Celigo Image Cytometer Instrumentation. Following this, 2or 24-h exposure to borax significantly altered the expression level of a number of genes in HepG2 cells, specifically 530 genes (384 upregulated and 146 downregulated) or 1,763 genes (1,044 upregulated and 719 downregulated) compared with the control group, respectively $(\geq 2$-fold; $\mathrm{P}<0.05$ ). Twenty downregulated genes were abundantly expressed in HepG2 cells under normal conditions. Furthermore, the growth of HepG2 cells was inhibited through the downregulation of PRUNE1, NBPF1, PPcaspase-1, UPF2 and MBTPS1 ( $\geq 1.5$-fold, $\mathrm{P}<0.05$ ).
\end{abstract}

Correspondence to: Professor Zhi-Gang Tang, Department of Pancreatic Surgery, Renmin Hospital of Wuhan University, Wuhan University, 99 Hubei Zhang Road, Wuchang, Wuhan, Hubei 430060 , P.R. China

E-mail:tzg7031@163.com

Key words: HepG2 cells, borax, gene expression profiling, Affymetrix, high-content screening
The dysregulated genes potentially serve important roles in various biological processes, including the inflammation response, stress response, cellular growth, proliferation, apoptosis and tumorigenesis/oncolysis.

\section{Introduction}

Boron is a naturally occurring element, representing $0.001 \%$ of the Earth's crust (1). Borax, which is also known as sodium tetraborate decahydrate $\left(\mathrm{Na}_{2} \mathrm{~B}_{4} \mathrm{O}_{7} 10 \mathrm{H}_{2} \mathrm{O}\right)$, is an important boron compound (2). In animals and humans, borax has been reported to be involved in metabolic processes associated with hormones and minerals (3). It has also been demonstrated to possess anti-inflammatory activity, indicating its therapeutic potential $(4,5)$. Boron supplementation in the diet (borax, $100 \mathrm{mg} / \mathrm{kg}$ ) has also been implicated to decrease lipid peroxidation and enhance antioxidant defense (6). Previous studies have suggested that the mechanism underlying the anti-inflammatory properties of borax involved the suppression of interleukin (caspase-)-8, indicating that borax is potentially applicable for a bactericidal agent $(7,8)$. However, numerous studies exploring the mutagenic properties of borax reported that its genotoxicity was nearly undetectable in bacteria and cultured mammalian cells $(9,10)$. Furthermore, previous studies revealed that different concentrations of borax affected cell survival and cell growth in addition to altering the properties of a few chromosomes in humans, which were possibly caused by various genetic defects resulting from abnormalities in human chromosome $(11,12)$. Additionally, borax has been widely known to have detrimental effects on lymphocyte proliferation, which is also highly vulnerable to induced sister chromatid exchange in human chromosomes (13). Thus, certain cellular toxicities indicated that those alterations were ascribed to genetic defects caused by borax in humans (14). Notably, it has been recently identified that borax treatment enhanced the resistance of DNA to titanium dioxide-induced 
damage (15). Taken together, numerous studies have focused on the application of borax for tumor prevention and demonstrated a strong inverse correlation between borax and various types of cancer, including prostate cancer, lung cancer, cervical cancer and hepatocellular carcinoma (HCC) (6-15). Although increasing studies have revealed various functions for borax, the underlying mechanisms of those effects remain unidentified, in particular regarding its genetic influences on various cells.

Our previous results indicated the effects of borax on tumor cells (HepG2) in vitro (Wu et al unpublished data). It was revealed that caspase--6 expression was increased following 2-h borax treatment in HepG2 cells and cell proliferation was inhibited following $24-\mathrm{h}$ borax $(4 \mathrm{mM})$ treatment. The numbers of living HepG2 cells and the borax concentrations were inversely correlated. Additionally, the 50\% inhibitory concentration of borax was estimated as $4 \mathrm{mM}$ (16). Although borax can be genotoxic at high doses, it is not highly mutagenic and does not easily form DNA adducts (17). Accordingly, borax is considered to induce oxidative stress through the depletion of glutathione and protein-bound sulfhydryl groups, which results in enhanced apoptosis and the production of reactive oxygen species $(18,19)$. In brief, borax is predominately non-genotoxic and epigenetic mechanisms are likely to underlie the mechanism for its induction of carcinogenesis, during which the expression of multiple essential genes are altered (12).

Theoretically, exposure of HepG2 cells to borax for either 2 or $24 \mathrm{~h}$ may induce alterations in the expression levels in various critical genes, and these genes may therefore serve essential roles in various signaling pathways. The present study explored gene expression alterations directly caused by treatments with doses of borax $(4 \mathrm{mM})$ in HepG2 cells for either 2 or $24 \mathrm{~h}$ and investigated the biological functions of those genes with significantly altered expression levels. Analysis of gene expression was performed through assessment of Affymetrix GeneChip data, followed by gene ontology (GO) analysis and pathway analysis.

\section{Materials and methods}

Cell culture. HepG2 cells were obtained from the China Center for Type Culture Collection (Wuhan University, Wuhan, China) and seeded in Dulbecco's modified Eagle's medium supplemented with $10 \%$ fetal bovine serum (FBS; cat. no. 10099-141; Gibco; Thermo Fisher Scientific, Inc., Waltham, MA, USA) 1 day prior to borax ( $4 \mathrm{mM}$; Tianjin Bodi Chemical Co. Ltd., Tianjin, China) treatment in a humidified $5 \% \mathrm{CO}_{2}$ incubator at $37^{\circ} \mathrm{C}$ for either 2 or $24 \mathrm{~h}$. Following 2- or 24-h treatment with $4 \mathrm{mM}$ borax, the culture medium was replenished with fresh media without borax.

RNA extraction and microarray hybridization. Following borax treatment, total RNA was extracted from HepG2 cells using TRIzol (cat. no. 3101-100; Invitrogen; Thermo Fisher Scientific, Inc.), followed by its purification using a miRNeasy Mini Kit (cat. no. 217004; Qiagen GmbH, Hilden, Germany). RNA integrity was also examined using an Agilent Bioanalyzer 2100 (grant no. G2938A; Agilent Technologies, Inc., Santa Clara, CA, USA). To obtain biotin-tagged cDNA, total RNA was subsequently amplified, labeled and purified using a WT
PLUS Reagent kit (cat. no. 902280; Affymetrix; Thermo Fisher Scientific, Inc.). Array hybridization was performed using an Affymetrix GeneChip Human Gene 2.0 ST Array (Affymetrix; Thermo Fisher Scientific, Inc.) and Hybridization Oven 645 (cat. no. 00-0331-220V; Affymetrix; Thermo Fisher Scientific, Inc.), the Gene Chip was subsequently washed using a Hybridization, Wash and Stain Kit (cat. no. 900720; Affymetrix; Thermo Fisher Scientific, Inc.) in a Fluidics Station 450 (cat. no. 00-0079, Affymetrix; Thermo Fisher Scientific, Inc.). A GeneChip Scanner 3000 (cat. no. 00-00213; Affymetrix; Thermo Fisher Scientific, Inc.) was used to scan the results, which were controlled by Command Console Software 4.0 (Affymetrix; Thermo Fisher Scientific, Inc.) to summarize probe cell intensity data, namely, the CEL files with default settings. Following this, CEL files were normalized according to gene and exon level using Expression Console Software 4.0 (Affymetrix; Thermo Fisher Scientific, Inc.). All of the procedures, including array hybridization and scanning, were independently performed according to a standard protocol (20) for microarray experiments $(n=3)$.

Validation of selected differentially expressed genes using reverse transcription-quantitative polymerase chain reaction $(R T-q P C R)$. Single-stranded cDNAs were converted from $2.0 \mu \mathrm{g}$ of total RNA extracted from cells using an RT kit (cat. no. M1701; Promega Corporation, Madison, WI, USA) with a temperature protocol of $72^{\circ} \mathrm{C}$ for $10 \mathrm{~min}$. qPCR analysis was performed using $2.0 \mu \mathrm{g}$ cDNA from each sample, pair-specific primers (Table I; Shanghai GeneChem Co., Ltd., Shanghai, China) and a SYBR green PCR Master Mix kit (cat. no. 639676; Takara Bio, Inc., Otsu, Japan). The thermocycling conditions used were as follows: 40 cycles at $95^{\circ} \mathrm{C}$ for $30 \mathrm{sec}$, $72^{\circ} \mathrm{C}$ for $45 \mathrm{sec}$, and $1 \mathrm{cycle}$ at $72^{\circ} \mathrm{C}$ for $10 \mathrm{~min}$. Quantitative measurement of the expression level of each gene was obtained by independent experiments $(n=3)$. Samples were normalized to the expression level of GAPDH. Additionally, according to the $2^{-\Delta \Delta \mathrm{Cq}}$ method (21), all of the results were detected as fold-change relative to the corresponding mRNA expression level in control cells.

Construction of adenoviral vectors. PCR was performed to amplify the encoding sequences of abundantly expressed genes. Gene interference RNA fragments $(100 \mu$ mol; three codon sites; Table II) of those amplified sequences were subcloned into a plasmid (300 ng/ $\mu \mathrm{l}$; Shanghai GeneChem Co., Ltd., Shanghai, China) backbone using the T4DNA ligase (cat. no. 170702; Takara Bio, Inc.) following the digestion of the restriction enzyme. The pGCScaspase--004-iRNA and the GV115-NC were co-transformed into Escherichia coli GRM602 with backbone vector GV115-NC for homologous recombination. The recombinant plasmid pAd-iRNA digested with PacI (Fermentas; Thermo Fisher Scientific, Inc.) was used to transfect 293T cells (Thermo Fisher Scientific, Inc.) using Lipofectamine 2000 (cat. no. 11668-027; Invitrogen; Thermo Fisher Scientific, Inc.) for further packaging and amplification of the viruses and used in all groups (including any controls). The time interval was $72 \mathrm{~h}$ between transfection and subsequent experimentation. A control group (non-targeting shRNA) and positive control (specific-targeting shRNA) were used. 
Table I. Sequences of primers employed for reverse transcription-quantitative polymerase chain reaction and their anticipated polymerase chain reaction product size.

\begin{tabular}{|c|c|c|c|}
\hline Primer & Forward $\left(5^{\prime}-3^{\prime}\right)$ & Reverse (5'-3') & Length (bp) \\
\hline $\mathrm{AZI} 2$ & AACACTAAGGAATCGAAACTCG & GAGCAAAATGGGAAGCAACAG & 186 \\
\hline BPGM & GCGTCTAAATGAGCGTCACTAT & GGAGGCGGGGTTACATTGTAG & 120 \\
\hline FAM102B & TGCTGGTGAATCTGAATCTTTG & CTGAGGTATTTCTCCTGTGGC & 236 \\
\hline FBXO9 & AGTGGATGTTTGAACTTGCTC & GCCTGTTCTTGTTTTCCTTTG & 121 \\
\hline HOXB5 & GACCACGATCCACAAATCAAGC & TGCCACTGCCATAATTTAGCAAC & 120 \\
\hline KIAA0430 & АCССТCСАCTTCGCCAATG & CTTTGCGAGTCTAACAGTGCG & 96 \\
\hline MBTPS1 & TTTGACACTGGGCTGAGCGAGAA & CGCCGATGCTGAGGTTTAACACG & 280 \\
\hline MYO10 & AGGAGGAAGTTCGGGAAGTGT & СТTCTCССCTGAGGAACATTG & 192 \\
\hline NBPF1 & GCCCTGATGTAGAAACTTC & ATTCTTAGCAGTACGATTCG & 146 \\
\hline PRUNE1 & GCCTCAAGTACCCACССТАAC & AGAGGGCACTCATCCACCAAG & 278 \\
\hline SETD5 & TACCTGGTGTCCTTGTGGTCT & CGCTTCTTGGGTTTGGTTCTT & 246 \\
\hline SNX13 & ATATCCTCTGCTTTGTGGGTG & AGATTCATCATCGCTTAGTGT & 281 \\
\hline TSR2 & ССCTGTTCCTCTGTCTGGCTCC & СTTCCTCACAATGACCGCACC & 169 \\
\hline TTLL4 & TCTTTCTGCTTGCGTTCGAG & AGAGGTATGGTTCTGTGGATGAG & 154 \\
\hline UPF2 & GGAGGTATCAAGTCCCGATGA & GTTGGGTAACTGCTGTAGGAAAG & 202 \\
\hline $\mathrm{RCN} 2$ & TTCAGGTCCCGGTTTGAGTCT & TCAAGCCTGCCATCGTTATCT & 252 \\
\hline USP16 & ATGAGGTCCAGTATTGTAGTTC & ACTGAGTCCTTTCACGGTTAT & 236 \\
\hline RASL11A & TATTCACGGCTGGTCTATGTCG & CACGCATTTGGACAGGGAATC & 120 \\
\hline PPIL1 & TGGGAATCATTGTGCTGGAG & CGAGGGTCACAAAGAACTGG & 291 \\
\hline MTIF2 & TGGTTGCTGGAAAATGTTGGG & CACGGGCTTTCTGATGTGCTT & 276 \\
\hline MAPK4 & CGGTGTCAATGGTTTGGTGC & GACGATGTTGTCGTGGTCCA & 151 \\
\hline LMAN2L & ACTCGCTGTCGAAGCCCTA & CTGGGGTAAGGCGGATATACT & 105 \\
\hline CENPN & TGAACTGACAACAATCCTGAAG & CTTGCACGCTTTTCCTCACAC & 129 \\
\hline CDCA8 & GCAGGAGAGCGGATTTACAAC & CTGGGCAATACTGTGCCTCTG & 141 \\
\hline EFR3A & GCTGTTCCGCTTTGCGTCCTC & AGAAGTTGGTCCAGTGCCTCC & 232 \\
\hline PPIP5K2 & ACTGGACAAAGCGGTTGCCTAT & TGGGATTATTTGGGTCACGGT & 167 \\
\hline
\end{tabular}

Cell culture and transfection. HepG2 cells were seeded in a 96-well black-bottom plate (1,500-2,500 cells/well; Corning Inc., Corning, NY, USA) filled with DMEM supplemented with $\mathrm{FBS}$ in a humidified incubator containing $5 \% \mathrm{CO}_{2}$ at $37^{\circ} \mathrm{C}$. The viral particles were added to serum-free medium when confluency reached $20-40 \%$. The media was replaced with fresh medium supplemented with FBS following $12 \mathrm{~h}$ of incubation. Cells were subsequently incubated for a further $72 \mathrm{~h}$ until the transfection rate reached 70-90\%. GFP expression was analyzed in HepG2 cells 48 and $72 \mathrm{~h}$ post-infection with AdGFP using fluorescence and light microscopy to determine the optimal transfection rate for subsequent experiments. Cells were subsequently collected for further use. Decreased expression of genes following treatment with shRNA was validated with RT-qPCR.

Cell proliferation assay. To identify the specific effects of those abundantly expressed genes on the proliferation of HepG 2 cells, these cells were infected with adenovirus, seeded in a 96-well plate $\left(2 \times 10^{3} /\right.$ well $)$ and cultured in a humidified incubator containing $5 \% \mathrm{CO}_{2}$ at $37^{\circ} \mathrm{C}$ for $24 \mathrm{~h}$. The plates were scanned using Celigo Image Cytometer Instrumentation (Nexcelom Bioscience Instruments (Shanghai) Co., Ltd.m Shanghai, China) $(22,23)$ to acquire images every $24 \mathrm{~h}$, measuring the number of viable cells with 5-day sequential monitoring. Gross quantitative analyses were independently performed $(n \geq 3)$, including the total number count, cell growth [shControl/experimental (transfected with RNAiMax) group, $>1.5$-fold change], position information and average integrated intensity of certain gated events for each fluorescence channel in individual wells.

Statistical analysis. A computational analysis of microarray data was performed using GeneSpring v12.0 (Agilent Technologies, Inc., Santa Clara, CA, USA). Based on a Student's t-test analysis, differentially expressed genes were filtered through statistical estimation of fold-changes from replicated samples (fold change $\geq 2.0$ ) using a P-value threshold $(\mathrm{P}<0.05)$. Distinguishable gene expression of those samples was demonstrated via hierarchical clustering, followed by heatmap generation. Additionally, GO and pathway analyses of differentially expressed genes were performed to determine the potential signaling pathways underlying their biological functions. Public data from bioinformatics resources (http://www.geneontology.org/) were utilized for GO enrichment analysis. Ingenuity Pathway Analysis was utilized to identify genes whose expression was changed by at least 2 -fold. 
Table II. Sequences of RNAis (three codon sites for each gene) employed to plasmid backbone.

\begin{tabular}{ll}
\hline Genes $\quad$ Codon sites & Target sequence \\
\hline
\end{tabular}

PRUNE1 PSC56272 TCGAGAAGTGCAGTCAGAT PSC56273 ATGTAAGTTGCCAACAGTT PSC56274 GCATGGATCTTGAACAGAA NBPF1 PSC29636 GCGAGAAGGCAGAGACGAA PSC29637 TGACAATGATCACGATGAA PSC29638 AGTCATATTCCCACAGTAA

PPIL1 PSC40511 ACAGAATTATCAAAGACTT PSC40512 AGGTTACTACAATGGCACA PSC40513 CTCCAAAGACCTGTAAGAA UPF2 PSC56248 GCCTAGATTCGAGCTTAAA PSC56249 CACCTAATGCAGATCTAAT PSC56250 CTTGTACCAAGGAAAGTAA MBTPS1 PSC56266 GTCGTGATAACACAGACTT PSC56267 TAACAATGTAATCATGGTT PSC56268 TGACTTTGAAGGTGGAATT SETD5 PSC56263 ACTTTGTAAGTCAGATGAT PSC56264 GCATTTAGATCATCACAAA PSC56265 ATCAGGAACACTGACCATT RCN2 PSC42354 GCTTCATCTAATTGATGAA PSC42355 GGTTTGAGTCTTGAAGAAT PSC42356 GATGTATGATCGTGTGATT

TSR2 PSC48385 CCAGTTTGTTAAACTCCTT PSC48386 CTTTACTCAGGATTTACTA PSC48387 AAAGAATGTGCGGTCTTTA

SNX13 PSC56275 CAATTCAATGAGGAATGTT PSC56276 CTGAAATCTTTGATGACAT PSC56277 TGATTCTAACTGCAACTAT

CENPN PSC32095 AACTGACAACAATCCTGAA PSC32096 AATGCAGTCTGGATTCGAA PSC32097 TAGTTCAGCACTTGATCCA

PPIP5K2 PSC36126 CTGTGATGTGTTTCAGCAT PSC36127 TGAAATTTCCACTAGCGAA PSC36128 AGAGATTCATTGGAGACTA USP16 PSC56254 GTGATATTCCACAAGATTT PSC56255 GAATAAACTGCTTTGTGAA PSC56256 CAGAAGAAATCATGTTTAT

TTLL4 PSC42339 TGGTCAGTTTGAACGAATT PSC42340 ACATGAAGTCTCCTAGTTT PSC42341 CCTCATCTACAGTCTCTTT

AZI2 PSC56260 ATATCGAGAGGTTTGCATT PSC56261 GAGGACAGAGGTGGAAACTCA PSC56262 CAGCTACAATCTAAAGAAGTA

LMAN2L PSC41153 CATAGTCATTGGTATCATA PSC41154 GGCATTTGACGATAATGAT PSC41155 AACGTTCGAGTACTTGAAA CDCA8 PSC24168 TTGACTCAAGGGTCTTCAA PSC24169 TGGATATCACCGAAATAAA PSC24170 CCTCCTTTCTGAAAGACTT BPGM PSC39388 AGCCATTAAGAAAGTAGAA PSC39389 CATTCTTCTGGAATTGGAT PSC39390 CGAAGTATTACGTGGCAAA
Table II. Continued.

\begin{tabular}{lll}
\hline Genes & Codon sites & \multicolumn{1}{c}{ Target sequence } \\
\hline MTIF2 & PSC56269 & AGACTCACATTTAGATGAA \\
& PSC56270 & CGTAATGGACATGTAATTT \\
& PSC56271 & AGGAGAAGAAATTCTTGAA \\
MAPK4 & PSC56251 & AAGGATCGTGGATCAACAT \\
& PSC56252 & GACCTCAATGGTGCGTGCA \\
& PSC56253 & TCGCGCAGTGGGTCAAGAG \\
FBXO9 & PSC56257 & AGAGGTTCAACAAACTCAT \\
& PSC56258 & TCAGATCATTGGAGCAGTT \\
& PSC56259 & TGATATAGAGTTCAAGATT \\
\hline
\end{tabular}

\section{Results}

Gene expression changes. Gene microarray analysis revealed that there were significant expressional alterations of 530 genes in HepG2 cells in the 2-h borax treatment group compared with the control group (fold change $\geq 2.0 ; \mathrm{P}<0.05$ ). Among them, 146 genes were downregulated and 384 genes were upregulated $(\mathrm{P}<0.05$; Fig. 1A). Furthermore, the expression levels of 1,763 genes were changed in HepG2 cells when the 24-h borax treatment group was compared with the control group (fold change $\geq 2.0 ; \mathrm{P}<0.05)$. Among these genes, 719 were downregulated and 1,044 were upregulated $(\mathrm{P}<0.05$; Fig. 1B).

Gene expression and GO analysis. Differentially expressed genes were stratified by treatment duration and presented as heatmaps either in red (upregulation) or green (downregulation), revealing an overall global change in expression for all genes $(\mathrm{P}<0.05$; Fig. 2). Furthermore, detectable differences in gene expression patterns among those groups were also revealed by hierarchical clustering analyses. To determine the biological dysfunctionality associated with the altered gene expression induced by borax treatment, public data from bioinformatics resources (http://www.geneontology.org/) were utilized for GO enrichment analysis. Based on the cellular components, biological processes and molecular functions of each gene, significantly enriched GO terms were also arranged correspondingly (Fig. 3).

Pathway analysis. To determine which pathways were involved, Ingenuity Pathway Analysis was utilized to identify genes whose expression was changed by at least 2 -fold. Furthermore, analyses of functional pathways indicated that the genes with expression levels that were significantly altered in cells from the 2-h treatment group compared with those in the control group were involved in seven KEGG pathways $(\mathrm{P}<0.01$; Table III). Furthermore, significantly altered genes in cells from the 24-h treatment group compared with those in the control group were primarily associated with five KEGG pathways $(\mathrm{P}<0.01$; Table IV).

Validation of the expression of genes by qPCR. To validate potentially valuable genes that were screened by microarray results, the results between the clustered selected transcripts and those from RT-qPCR were compared (Fig. 2). Following 
A

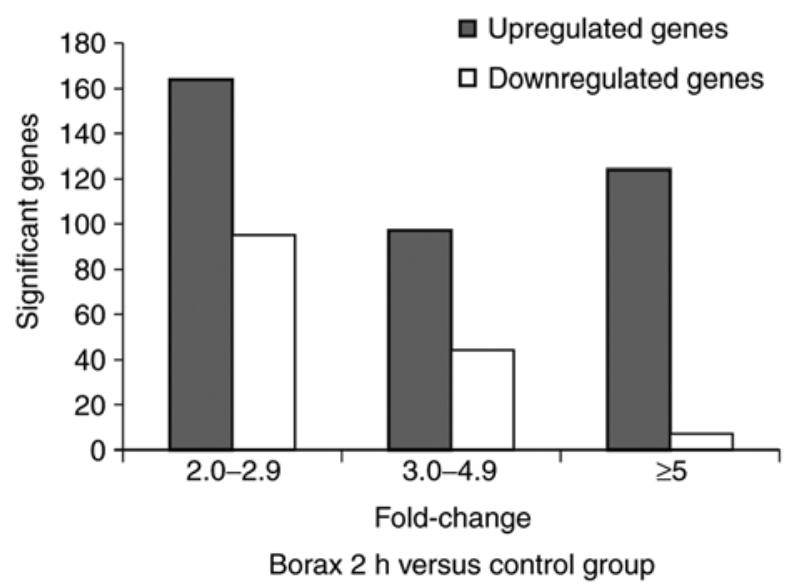

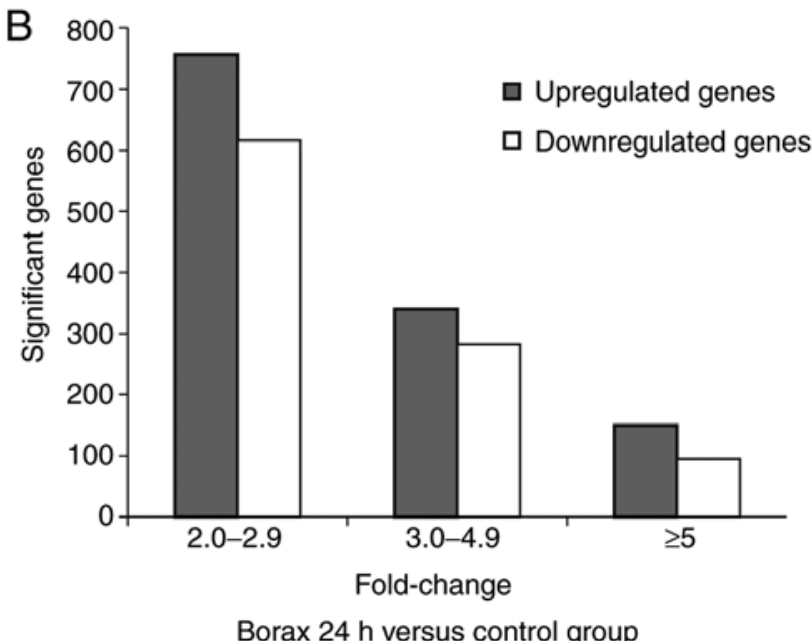

Borax $24 \mathrm{~h}$ versus control group

Figure 1. Upregulated and downregulated genes following treatment with $4 \mathrm{mM}$ borax in HepG2 cells after 2 and $24 \mathrm{~h}$ were determined using gene microarray analysis ( 2 and $24 \mathrm{~h}$ groups vs. control group, $\mathrm{P}<0.05$ ), respectively (over 2 -fold change).
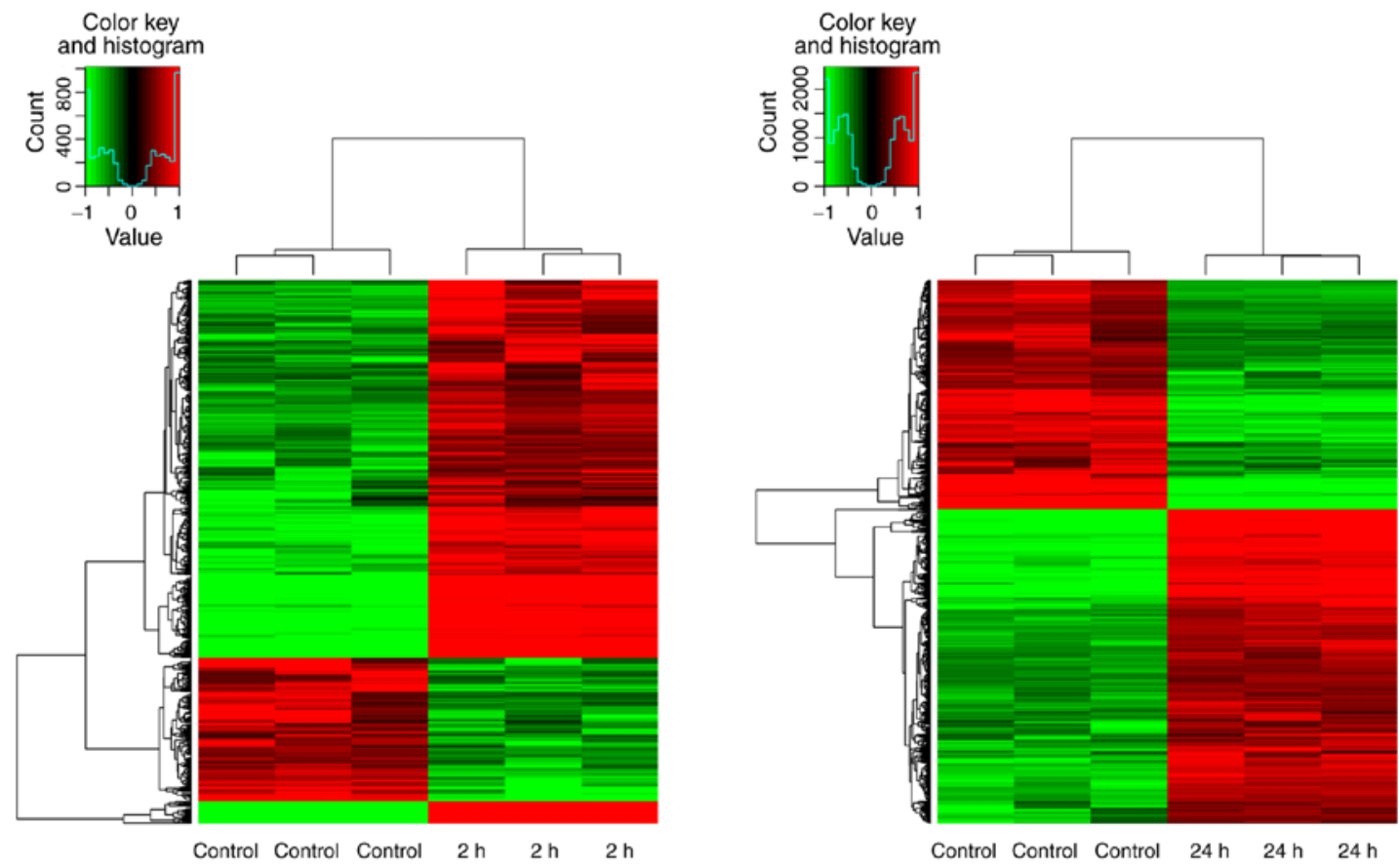

Figure 2. Heatmaps of differentially expressed genes due to borax treatments in HepG2 cells for 2 and $24 \mathrm{~h}$ ( $>2$-fold change, $\mathrm{P}<0.05)$. Red indicates upregulation whereas green indicates downregulation of gene expression relative to control (untreated cells).

borax treatment, 26 downregulated genes were identified on the basis of fold-change threshold, and the potentially functional correlation of caspase--6 or P53 signaling with proliferation in HepG2 cells was suggested. Additionally, RT-qPCR also revealed a few abundantly expressed genes, including AZI2, BPGM, FBXO9, MBTPS1, NBPF1, PRUNE1, SNX13, SETD5, TSR2, TTLL4, UPF2, RCN2, USP16, PPcaspase-1, MTIF2, MAPK4, LMAN2L, CENPN, CDCA8 and PPIP5K2, in HepG2 cells with no borax treatment.

Effects of abundantly expressed genes on cell proliferation. HepG2 cells infected with recombinant adenovirus were cultured for 48-72 h. When adenoviral green fluorescent protein (AdGFP) reached over $80 \%$, recombinant adenovirus was considered to be efficiently infected HepG2 cells in vitro (Fig. 4), and decreased expression of genes was established following transfection with each shRNA (Fig. 5). On the 5th day following the infection, the proliferation of iRNA-treated HepG2 cells was significantly suppressed (fold change $\geq 1.5$ ) compared with those in the control group $(\mathrm{P}<0.05)$. Furthermore, the target genes of RNAi fragments included PRUNE1, NBPF1, PPcaspase-1, UPF2 and MBTPS1 (fold change $\geq 1.50$; Fig. 6 ). These findings indicted that, compared with control group cells, cell proliferation in the shRNA group was significantly reduced (fold change $\geq 1.5$ ). Therefore it was inferred that the target gene of RNA lentivirus in the shRNA group was tumor cells proliferation-related positive gene. 
A

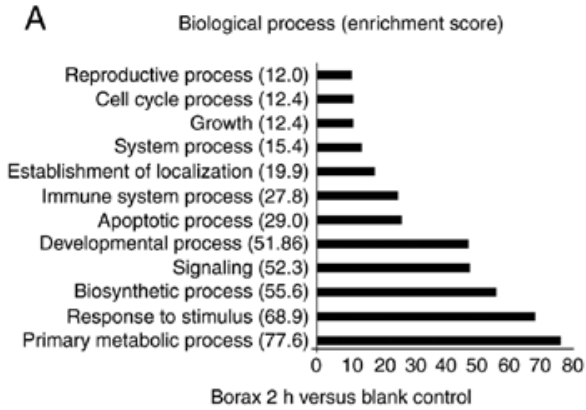

C

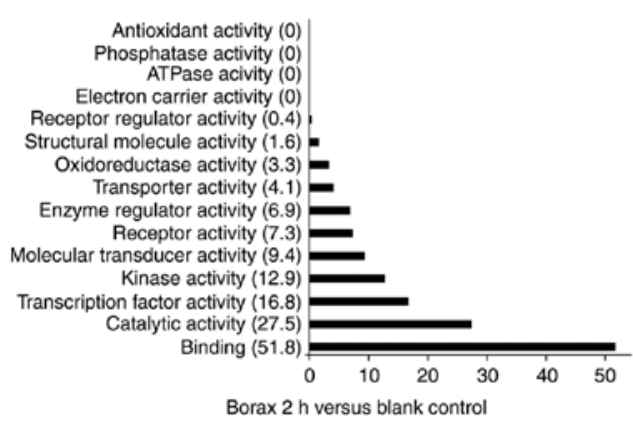

E

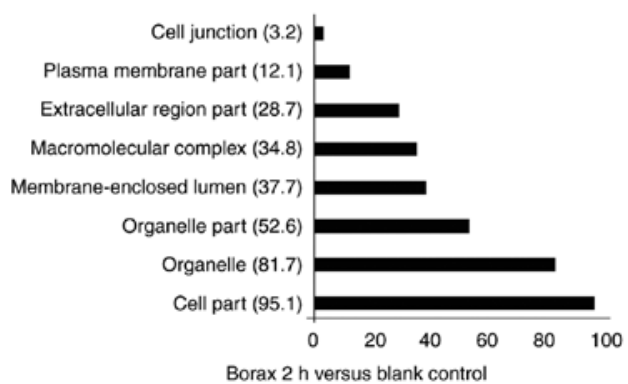

B Biological process (enrichment score)

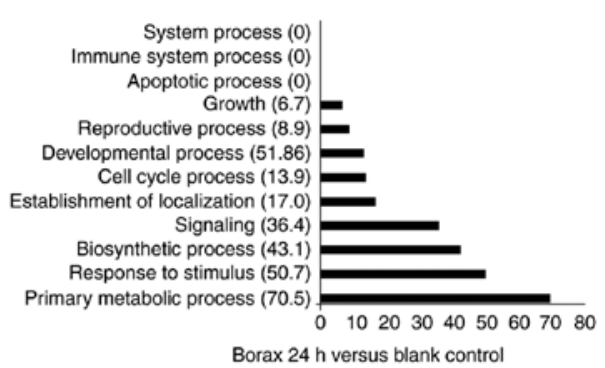

Borax $24 \mathrm{~h}$ versus blank control

D

Molecular function (enrichment score)

Electron carrier activity (0)

Receptor regulator activity $(0)$

Structural molecule activity (0)

Enzyme regulator activity (0) Receptor activity (0)

Molecular transducer activity (0)

Antioxidant activity (0.9)

Phosphatase activity (2.4)

ATPase acivity (3.7)

Oxidoreductase activity (5.9) Kinase activity (6.1)

Transcription factor activity (8.5)

Transferase activity (16.9)

Catalytic activity $(38.3)$

Binding (49.5)

Borax $24 \mathrm{~h}$ versus blank contro

$\mathrm{F}$

Cellular component (enrichment score)

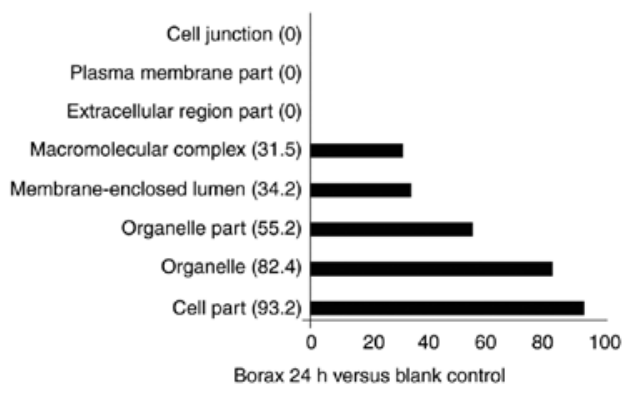

Figure 3. Enriched GO terms according to biological processes, molecular functions, and cellular components. GO terms are ordered by enrichment score with the highest enriched term at the bottom of the list. Differentially expressed transcripts involved in the term (count) $\mathrm{P}<0.05$ with and fold change $>2.0$ were included. GO, gene ontology.

\section{Discussion}

Boron is a naturally abundant element on the earth (24). Notably, borax is a boron compound, which plays essential roles in many industries and in daily life (25). Currently, several boron-containing molecules have been applied for the treatment of multiple diseases, including inflammation, diabetes and cancer $(26,27)$. Some of these treatments have produced positive results in preclinical and clinical trials $(28,29)$. For instance, previous studies revealed boric acid/borax mediated protection against $\mathrm{TiO}_{2}$ genotoxicity in peripheral blood cells (30). In addition, borax mediated the stimulation of sister chromatid exchange in human chromosomes and/or lymphocyte proliferation (1). Furthermore, a previous study revealed that peripheral blood cells with aflatoxin B1-induced genetic damage were sufficiently rescued by borax treatment, which has also been indicated to be an effective antiepileptic drug $(31,32)$.

The properties of borax are also considered to be correlated with genetic defects and genotoxicity. Specifically, it is widely accepted that when borax is applied at high concentrations, it is cytotoxic to mammalian cells, although cell transformation assays show that borax treatment is weakly mutagenic and not oncogenic (33). In our previous study, it was indicated that borax induced a strong increase in caspase--6 production, which was accompanied by the enhanced expression of p53-modulated genes, including p21, Bax and Puma (16). Considering that the precise regulation of borax-induced genotoxicity has not been well defined, novel mechanisms underlying the genetic actions and potential new biological effects of borax on various cell-types require more insight.

In the present study, microarray analysis indicated that the expression levels of 530 genes were changed in HepG2 cells in the 2-h treatment group. Among them, 146 were downregulated and 384 were upregulated. Notably, MYO10, one of the downregulated genes, encodes a member of the myosin superfamily, which mediates the migration and invasion of tumor cells, suggesting that it contributes to the metastatic phenotype, possibly via its direct involvement in the assembly of molecular motors $(34,35)$. miR-4521 was also downregulated, which is closely correlated with signal transduction, mediating DNA binding, receptor activity and other processes (36). The DDIT3 gene, which encodes a suppressor protein that primarily inhibits mTOR signaling under stress conditions 
Table III. Differentially expressed genes involved in signal transduction ( $2 \mathrm{~h}$ vs. Control group).

\begin{tabular}{|c|c|c|c|c|c|c|}
\hline $\begin{array}{l}\text { Pathway/ } \\
\text { genebank ID }\end{array}$ & Probe_Set_ID & $\begin{array}{l}\text { Gene } \\
\text { symbol }\end{array}$ & $\begin{array}{l}\text { Description of } \\
\text { expression product }\end{array}$ & $\begin{array}{l}\text { Fold } \\
\text { change }\end{array}$ & P-values & $\begin{array}{l}\text { Regulation after } \\
\text { borax treeatment }\end{array}$ \\
\hline \multicolumn{7}{|c|}{ hsa04010:MAPK signaling pathway } \\
\hline NM_001202233 & TC12000414.hg.1 & NR4A1 & $\begin{array}{l}\text { Nuclear receptor subfamily } 4 \text {, } \\
\text { group A, member } 1\end{array}$ & 21.7 & 0.000881 & Up \\
\hline NM_005252 & TC11001948.hg.1 & FOS & $\begin{array}{l}\text { FBJ murine osteosarcoma viral } \\
\text { oncogene homolog }\end{array}$ & 11.3 & 0.000164 & Up \\
\hline NM_001199741 & TC01000745.hg.1 & GADD45A & $\begin{array}{l}\text { Growth arrest and } \\
\text { DNA-damage-inducible, alpha }\end{array}$ & 10.7 & 0.000054 & Up \\
\hline NM_004419 & TC10000801.hg.1 & DUSP5 & Dual specificity phosphatase 5 & 10.6 & 0.000096 & Up \\
\hline NM_000575 & TC02002218.hg.1 & IL1A & Interleukin-1, alpha & 8.3 & 0.005040 & $\mathrm{Up}$ \\
\hline NM_001394 & TC08001099.hg.1 & DUSP4 & Dual specificity phosphatase 4 & 5.6 & 0.002509 & Up \\
\hline NM_005354 & TC19001285.hg.1 & JUND & Jun D proto-oncogene & 3.4 & 0.001100 & $\mathrm{Up}$ \\
\hline NM_015675 & TC19000055.hg.1 & GADD45B & $\begin{array}{l}\text { Growth arrest and } \\
\text { DNA-damage-inducible, beta }\end{array}$ & 3.3 & 0.000382 & Up \\
\hline NM_001195053 & TC12001625.hg.1 & DDIT3 & $\begin{array}{l}\text { DNA-damage-inducible } \\
\text { transcript } 3\end{array}$ & 2.3 & 0.005761 & Up \\
\hline NM_030640 & TC12001255.hg.1 & DUSP16 & Dual specificity phosphatase 16 & 2.3 & 0.000079 & Up \\
\hline NM_000576 & TC02002219.hg.1 & IL1B & Interleukin-1, beta & 2.1 & 0.016505 & Up \\
\hline NM_004651 & TC05001184.hg.1 & MYO10 & Myosin 10 & -7.17 & 0.001269 & Down \\
\hline NM_005345 & TC06000384.hg.1 & HSPA1A & Heat shock $70 \mathrm{kDa}$ protein $1 \mathrm{~A}$ & -4.2 & 0.011012 & Down \\
\hline NM_005346 & TC06000385.hg.1 & HSPA1B & Heat shock $70 \mathrm{kDa}$ protein $1 \mathrm{~B}$ & -4.3 & 0.010610 & Down \\
\hline NM_002228 & TC01001927.hg.1 & JUN & Jun proto-oncogene & -2.1 & 0.000287 & Down \\
\hline
\end{tabular}

hsa04064:NF-kappa B signaling pathway

\begin{tabular}{|c|c|c|c|c|c|c|}
\hline NM_000963 & TC01003638.hg.1 & PTGS2 & $\begin{array}{l}\text { Prostaglandin-endoperoxide } \\
\text { synthase } 2 \text { (prostaglandin G/H } \\
\text { synthase and cyclooxygenase) }\end{array}$ & 75.7 & 0.000000 & Up \\
\hline NM_006290 & TC06001027.hg.1 & TNFAIP3 & $\begin{array}{l}\text { Tumor necrosis factor, } \\
\text { alpha-induced protein } 3\end{array}$ & 68.3 & 0.000000 & Up \\
\hline NM_020529 & TC14001036.hg.1 & NFKBIA & $\begin{array}{l}\text { Nuclear factor of kappa light } \\
\text { polypeptide gene enhancer } \\
\text { in B-cells inhibitor, alpha }\end{array}$ & 9.2 & 0.000014 & Up \\
\hline NM_001165 & TC11000956.hg.1 & BIRC3 & $\begin{array}{l}\text { Baculoviral IAP repeat } \\
\text { containing } 3\end{array}$ & 3.7 & 0.000004 & $\mathrm{Up}$ \\
\hline NM_002089 & TC04001286.hg.1 & CXCL2 & $\begin{array}{l}\text { Chemokine (C-X-C motif) } \\
\text { ligand } 2\end{array}$ & 4.0 & 0.010873 & Up \\
\hline NM_015675 & TC19000055.hg.1 & GADD45B & $\begin{array}{l}\text { Growth arrest and } \\
\text { DNA-damage-inducible, beta }\end{array}$ & 3.3 & 0.000382 & Up \\
\hline NM_000576 & TC02002219.hg.1 & IL1B & Interleukin-1, beta & 2.1 & 0.016505 & $\mathrm{Up}$ \\
\hline
\end{tabular}

hsa04621:NOD-like receptor signaling pathway

\begin{tabular}{|c|c|c|c|c|c|}
\hline NM_006290 & TC06001027.hg.1 & TNFAIP3 & $\begin{array}{l}\text { Tumor necrosis factor, } \\
\text { alpha-induced protein } 3\end{array}$ & 68.3 & 0.000000 \\
\hline NM_020529 & TC14001036.hg.1 & NFKBIA & $\begin{array}{l}\text { Nuclear factor of kappa light } \\
\text { polypeptide gene enhancer in } \\
\text { B-cells inhibitor, alpha }\end{array}$ & 9.2 & 0.000014 \\
\hline NM_002089 & TC04001286.hg.1 & CXCL2 & $\begin{array}{l}\text { Chemokine (C-X-C motif) } \\
\text { ligand } 2\end{array}$ & 4.0 & 0.010873 \\
\hline NM_001165 & TC11000956.hg.1 & BIRC3 & $\begin{array}{l}\text { Baculoviral IAP repeat } \\
\text { containing } 3\end{array}$ & 3.7 & 0.000004 \\
\hline
\end{tabular}


Table III. Continued.

\begin{tabular}{lllllll}
\hline $\begin{array}{l}\text { Pathway/ } \\
\text { genebank ID }\end{array}$ & Probe_Set_ID & $\begin{array}{c}\text { Gene } \\
\text { symbol }\end{array}$ & $\begin{array}{c}\text { Description of } \\
\text { expression product }\end{array}$ & $\begin{array}{c}\text { Fold } \\
\text { change }\end{array}$ & $\begin{array}{r}\text { Regulation after } \\
\text { P-values } \\
\text { borax treeatment }\end{array}$ \\
\hline NM_000576 & TC02002219.hg.1 & IL1B & Interleukin-1, beta & 2.1 & 0.016505 & Up \\
NM_000600 & TC05002383.hg.1 & IL6 & Interleukin-6 & 2.4 & 0.007231 & Up \\
NM_100616406 & TC17000132.hg.1 & MIR4521 & MicroRNA 4521 & -6.61 & 0.000125 & Down \\
\hline
\end{tabular}

hsa04115:p53 signaling pathway

\begin{tabular}{|c|c|c|c|c|c|}
\hline NM_001199741 & TC01000745.hg.1 & GADD45A & $\begin{array}{l}\text { Growth arrest and } \\
\text { DNA-damage-inducible, alpha }\end{array}$ & 10.7 & 0.000054 \\
\hline NM_003246 & TC15000270.hg.1 & THBS1 & Thrombospondin 1 & 6.5 & 0.002300 \\
\hline NM_000602 & TC07000643.hg.1 & SERPINE1 & $\begin{array}{l}\text { Serpin peptidase inhibitor, clade } \\
\text { E (nexin, plasminogen activator } \\
\text { inhibitor type } 1 \text { ), member } 1\end{array}$ & 4.7 & 0.010348 \\
\hline NM_021127 & TC18000213.hg.1 & PMAIP1 & $\begin{array}{l}\text { Phorbol-12-myristate-13- } \\
\text { acetate-induced protein } 1\end{array}$ & 4.7 & 0.000034 \\
\hline NM_015675 & TC19000055.hg.1 & GADD45B & $\begin{array}{l}\text { Growth arrest and DNA- } \\
\text { damage-inducible, beta }\end{array}$ & 3.3 & 0.000382 \\
\hline
\end{tabular}

hsa04141:Protein processing in endoplasmic reticulum

\begin{tabular}{|c|c|c|c|c|c|c|}
\hline NM_014330 & TC19000711.hg.1 & PPP1R15A & $\begin{array}{l}\text { Protein phosphatase } 1, \\
\text { regulatory subunit } 15 \mathrm{~A}\end{array}$ & 4.4 & 0.006746 & Up \\
\hline NM_018566 & TC01003773.hg.1 & YOD1 & $\begin{array}{l}\text { YOD1 OTU deubiquinating } \\
\text { enzyme } 1 \text { homolog }\end{array}$ & 3.7 & 0.000181 & Up \\
\hline NM_001433 & TC17001796.hg.1 & ERN1 & $\begin{array}{l}\text { Endoplasmic reticulum to } \\
\text { nucleus signaling } 1\end{array}$ & 2.6 & 0.000008 & Up \\
\hline NM_001195053 & TC12001625.hg.1 & DDIT3 & $\begin{array}{l}\text { DNA-damage-inducible } \\
\text { transcript } 3\end{array}$ & 2.3 & 0.005761 & Up \\
\hline NM_005346 & TC06000385.hg.1 & HSPA1B & Heat shock $70 \mathrm{kDa}$ protein $1 \mathrm{~B}$ & -4.3 & 0.010610 & Down \\
\hline NM_005345 & TC06000384.hg.1 & HSPA1A & Heat shock $70 \mathrm{kDa}$ protein $1 \mathrm{~A}$ & -4.2 & 0.011012 & Down \\
\hline NM_003791 & TC16001307.hg.1 & MBTPS1 & $\begin{array}{l}\text { Membrane-bound transcription } \\
\text { factor peptidase, site } 1\end{array}$ & -3.2 & 0.000643 & Down \\
\hline NM_001172415 & TC09001009.hg.1 & BAG1 & BCL2-associated athanogene & -2.1 & 0.000440 & Down \\
\hline
\end{tabular}

hsa04668:TNF signaling pathway

\begin{tabular}{|c|c|c|c|c|c|c|}
\hline NM_000963 & TC01003638.hg.1 & PTGS2 & $\begin{array}{l}\text { Prostaglandin-endoperoxide } \\
\text { synthase } 2 \text { (prostaglandin G/H } \\
\text { synthase and cyclooxygenase) }\end{array}$ & 75.7 & 0.000000 & Up \\
\hline NM_006290 & TC06001027.hg.1 & TNFAIP3 & $\begin{array}{l}\text { Tumor necrosis factor, } \\
\text { alpha-induced protein } 3\end{array}$ & 68.3 & 0.000000 & Up \\
\hline NM_001168319 & TC06000087.hg.1 & EDN1 & Endothelin 1 & 13.1 & 0.000004 & Up \\
\hline NM_005252 & TC11001948.hg.1 & FOS & $\begin{array}{l}\text { FBJ murine osteosarcoma viral } \\
\text { oncogene homolog }\end{array}$ & 11.3 & 0.000164 & Up \\
\hline NM_020529 & TC14001036.hg.1 & NFKBIA & $\begin{array}{l}\text { Nuclear factor of kappa light } \\
\text { polypeptide gene enhancer in } \\
\text { B-cells inhibitor, alpha }\end{array}$ & 9.2 & 0.000014 & Up \\
\hline NM_002089 & TC04001286.hg.1 & CXCL2 & $\begin{array}{l}\text { Chemokine (C-X-C motif) } \\
\text { ligand } 2\end{array}$ & 4.0 & 0.010873 & Up \\
\hline NM_001165 & TC11000956.hg.1 & BIRC3 & $\begin{array}{l}\text { Baculoviral IAP repeat } \\
\text { containing } 3\end{array}$ & 3.7 & 0.000004 & Up \\
\hline NM_001130046 & TC02001364.hg.1 & CCL20 & $\begin{array}{l}\text { Chemokine (C-C motif) } \\
\text { ligand } 20\end{array}$ & 3.0 & 0.002008 & Up \\
\hline
\end{tabular}


Table III. Continued.

\begin{tabular}{|c|c|c|c|c|c|c|}
\hline $\begin{array}{l}\text { Pathway/ } \\
\text { genebank ID }\end{array}$ & Probe_Set_ID & $\begin{array}{c}\text { Gene } \\
\text { symbol }\end{array}$ & $\begin{array}{c}\text { Description of } \\
\text { expression product }\end{array}$ & $\begin{array}{c}\text { Fold } \\
\text { change }\end{array}$ & P-values & $\begin{array}{l}\text { Regulation after } \\
\text { borax treeatment }\end{array}$ \\
\hline NM_000600 & TC05002383.hg.1 & IL6 & Interleukin-6 & 2.4 & 0.007231 & Up \\
\hline NM_000576 & TC02002219.hg.1 & IL1B & Interleukin-1, beta & 2.1 & 0.016505 & $\mathrm{Up}$ \\
\hline NM_003955 & TC17001917.hg.1 & SOCS3 & $\begin{array}{l}\text { Suppressor of cytokine } \\
\text { signaling } 3\end{array}$ & 2.1 & 0.003726 & $\mathrm{Up}$ \\
\hline NM_002228 & TC01001927.hg.1 & JUN & Jun proto-oncogene & -2.1 & 0.000287 & Down \\
\hline
\end{tabular}

hsa04620:Toll-like receptor signaling pathway

\begin{tabular}{|c|c|c|c|c|c|c|}
\hline NM_005252 & TC11001948.hg.1 & FOS & $\begin{array}{l}\text { FBJ murine osteosarcoma } \\
\text { viral oncogene homolog }\end{array}$ & 11.3 & 0.000164 & Up \\
\hline NM_020529 & TC14001036.hg.1 & NFKBIA & $\begin{array}{l}\text { Nuclear factor of kappa } \\
\text { light polypeptide gene enhancer } \\
\text { in B-cells inhibitor, alpha }\end{array}$ & 9.2 & 0.000014 & $\mathrm{Up}$ \\
\hline NM_000600 & TC05002383.hg.1 & IL6 & Interleukin-6 & 2.4 & 0.007231 & $\mathrm{Up}$ \\
\hline NM_000576 & TC02002219.hg.1 & IL1B & Interleukin-1, beta (IL1B) & 2.1 & 0.016505 & $\mathrm{Up}$ \\
\hline NM_002228 & TC01001927.hg.1 & JUN & Jun proto-oncogene & -2.1 & 0.000287 & Down \\
\hline
\end{tabular}

A

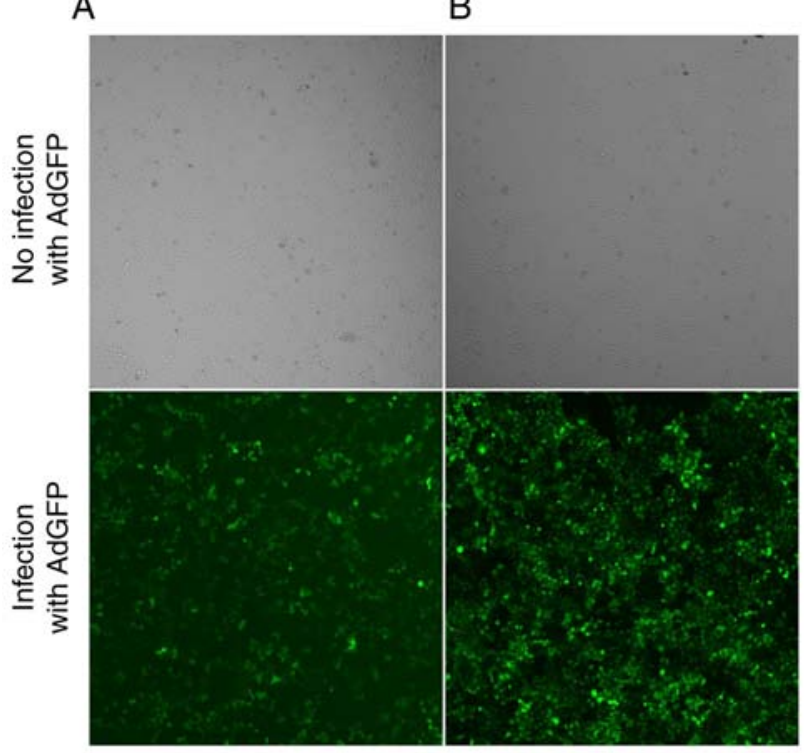

Figure 4. Efficiency of adenovirus infection in HepG2 cells. GFP expression was analyzed in HepG 2 cells 48 and 72 h post-infection with AdGFP using fluorescence (lower panels) and light (phase-contrast; upper panels) microscopy (magnification, $\mathrm{x} 100$ ) to determine the optimal transfection rate for subsequent experiments. (A) (48 h) $40 \%$ and (B) (72 h) $80 \%$ of cells exhibited GFP expression, respectively. AdGFP, adenoviral green fluorescent protein.

and is partially involved in cancer progression (37), was also downregulated with borax treatment. Heat shock protein (HSP) 25 protein is encoded by the HSP $\beta-1$ gene. HSP $\beta-1$ is a member of the HSP family (38) and is abundantly expressed in various types of cancer associated with poor prognosis and resistance to chemotherapy, possibly through their aggressive tumor behavior and metastasis (39). In the present study, HSP $\beta-1$ was also significantly downregulated. Early growth response protein 1 , which is involved in the initial stage of the inflammatory response, possibly through its critical roles as a tumor suppressor or promoter (40), was upregulated following 2-h borax treatment in the present study. Furthermore, prostaglandin-endoperoxide synthase 2, a principal inflammatory mediator and a UV-inducible enzyme the catalyzes the first step in the synthesis of prostaglandin E2 (41), was also upregulated. Additionally, TNFAIP3 and caspase--6, which are associated with inflammation and stress reaction (42), were also found to be upregulated. Notably, TNFAIP3 acts as a critical molecular switch to discriminate tumor necrosis factor-induced $N F-\kappa B$ signaling from the activated JNK signaling pathways in hepatocytes when stimulated with varying cytokine concentrations under normal or pathological conditions (43). These findings implicate downregulated/upregulated genes following borax treatment impact the migration and invasion of tumor cells, DNA binding signal transduction, inflammation and stress reactions. However, the specific mechanisms involved require further study.

The expression levels of 1,763 genes were changed in cells from the 24-h treatment group compared with those in the control group. Specifically, 719 genes were downregulated and 1,044 genes were upregulated (Fig. 1). Among them, the downregulated genes included B3GALT6, a critical enzyme catalyzing the formation of the tetrasaccharide linkage region, the mutation of which results in proteoglycan maturation defects (44). In the present study, FAM20B was downregulated in the 24-h treatment group. Notably, it was previously indicated that FAM20B deletion is associated with Ehlers-Danlos syndrome $(45,46)$. UBE4B was also downregulated in cells from the 24-h treatment group in the present study. A previous study revealed that silencing of UBE4B expression inhibited the proliferation, colony formation, migration and invasion of liver cancer cells in vitro, and resulted in significant apoptosis. Therefore, it was suggested that this gene may be a good prognostic candidate for liver cancer (47). The overexpression of UBE4B, which is 
Table IV. Differentially expressed genes involved in signal transduction ( $24 \mathrm{~h}$ vs. control group).

\begin{tabular}{|c|c|c|c|c|}
\hline $\begin{array}{l}\text { Pathway/ } \\
\text { Genebank ID }\end{array}$ & Probe_Set_ID & $\begin{array}{l}\text { Gene } \\
\text { symbol }\end{array}$ & $\begin{array}{c}\text { Description of } \\
\text { expression product }\end{array}$ & $\begin{array}{cc}\begin{array}{c}\text { Fold } \\
\text { change P-values }\end{array} & \text { Regulation after } \\
\text { borax treeatment }\end{array}$ \\
\hline
\end{tabular}

hsa04110:Cell cycle

\begin{tabular}{|c|c|c|c|c|c|c|}
\hline NM_002392 & TC12000606.hg.1 & MDM2 & $\begin{array}{l}\text { Mdm2, p53 E3 ubiquitin protein } \\
\text { ligase homolog }\end{array}$ & 13.8 & 0.00010 & Up \\
\hline NM_001199741 & TC01000745.hg.1 & GADD45A & Growth arrest and & 7.9 & 0.00006 & $\mathrm{Up}$ \\
\hline NM_000389 & TC06000532.hg.1 & CDKN1A & $\begin{array}{l}\text { DNA-damage-inducible, alpha } \\
\text { Cyclin-dependent kinase inhibitor } \\
\text { 1A (p21, Cip1) }\end{array}$ & 4.4 & 0.00015 & Up \\
\hline NM_001259 & TC07001603.hg.1 & CDK6 & Cyclin-dependent kinase 6 & 4.3 & 0.00013 & $\mathrm{Up}$ \\
\hline NM_001079846 & TC16000823.hg.1 & CREBBP & CREB binding protein (CREBBP) & 3.0 & 0.00007 & $\mathrm{Up}$ \\
\hline NM_001799 & TC05000301.hg.1 & CDK7 & Cyclin-dependent kinase 7 & 2.8 & 0.00039 & $\mathrm{Up}$ \\
\hline NM_007637 & TC10001228.hg.1 & ZNF84 & Zinc finger protein 84 & 2.42 & 0.00063 & Up \\
\hline NM_001789 & TC03001374.hg.1 & CDC25A & Cell division cycle 25 homolog A & 2.4 & 0.00041 & Up \\
\hline NM_002553 & TC07001724.hg.1 & ORC5 & Origin recognition complex, subunit 5 & 2.3 & 0.00012 & $\mathrm{Up}$ \\
\hline ВC012827 & TC01000545.hg.1 & CDC20 & Cell division cycle 20 homolog & 2.2 & 0.00364 & $\mathrm{Up}$ \\
\hline NM126792 & TC05001184.hg.1 & B3GALT6 & $\begin{array}{l}\text { Beta } 1,3 \text {-galactosyltransferase } \\
\text { polypeptide } 6\end{array}$ & -18.97 & 0.00000 & Down \\
\hline NM009917 & TC06001313.hg.1 & FAM20B & $\begin{array}{l}\text { Family with sequence similarity } 20 \text {, } \\
\text { member B }\end{array}$ & -5.13 & 0.00002 & Down \\
\hline NM_001262 & TC01000619.hg.1 & CDKN2C & $\begin{array}{l}\text { Cyclin-dependent kinase inhibitor 2C } \\
\text { (p18, inhibits CDK4) }\end{array}$ & -4.8 & 0.00364 & Down \\
\hline NM_003318 & TC06000761.hg.1 & TTK & TTK protein kinase & -3.7 & 0.00008 & Down \\
\hline NM_001237 & TC04001516.hg.1 & CCNA2 & Cyclin A2 (CCNA2) & -3.5 & 0.00007 & Down \\
\hline NM_004701 & TC15000449.hg.1 & CCNB2 & Cyclin B2 (CCNB2) & -2.7 & 0.00011 & Down \\
\hline NM_005611 & TC16000448.hg.1 & RBL2 & Retinoblastoma-like 2 (p130) & -2.6 & 0.00001 & Down \\
\hline NM_001178138 & TC03001849.hg.1 & TFDP2 & $\begin{array}{l}\text { Transcription factor Dp-2 } \\
\text { (E2F dimerization partner 2) }\end{array}$ & -2.5 & 0.00001 & Down \\
\hline NM_001786 & TC02001182.hg.1 & CDK1 & Cyclin-dependent kinase 1 & -2.5 & 0.00163 & Down \\
\hline NM_002388 & TC06001799.hg.1 & MCM3 & $\begin{array}{l}\text { Minichromosome maintenance } \\
\text { complex component } 3\end{array}$ & -2.5 & 0.00000 & Down \\
\hline NM_057749 & TC08001438.hg.1 & CCNE2 & Cyclin E2 (CCNE2) & -2.4 & 0.00622 & Down \\
\hline NM_001042749 & TC0X000606.hg.1 & STAG2 & Stromal antigen 2 (STAG2 & -2.2 & 0.00017 & Down \\
\hline NM_005915 & TC02002376.hg.1 & MCM6 & $\begin{array}{l}\text { Minichromosome maintenance } \\
\text { complex component } 6\end{array}$ & -2.1 & 0.00019 & Down \\
\hline NM_001136197 & TC19000070.hg.1 & FZR1 & Fizzy/cell division cycle 20 related 1 & -2.1 & 0.00348 & Down \\
\hline NM_022809 & TC05001829.hg.1 & $\mathrm{CDC} 25 \mathrm{C}$ & Cell division cycle 25 homolog $\mathrm{C}$ & -2.1 & 0.00092 & Down \\
\hline
\end{tabular}

hsa04115:p53 signaling pathway

\begin{tabular}{|c|c|c|c|c|c|c|}
\hline NM_002392 & TC12000606.hg.1 & MDM2 & $\begin{array}{l}\text { Mdm2, p53 E3 ubiquitin protein } \\
\text { ligase homolog }\end{array}$ & 13.8 & 0.00010 & $\mathrm{Up}$ \\
\hline NM_008870 & TC13000386.hg.1 & IER3 & Immediate early response 3 & 8.47 & 0.00200 & $\mathrm{Up}$ \\
\hline NM_001199741 & TC01000745.hg.1 & GADD45A & $\begin{array}{l}\text { Growth arrest and } \\
\text { DNA-damage-inducible, alpha }\end{array}$ & 7.9 & 0.00006 & $\mathrm{Up}$ \\
\hline NM_021127 & TC18000213.hg.1 & PMAIP1 & $\begin{array}{l}\text { Phorbol-12-myristate-13-acetate- } \\
\text { induced protein } 1\end{array}$ & 6.1 & 0.00001 & $\mathrm{Up}$ \\
\hline NM_000389 & TC06000532.hg.1 & CDKN1A & Cyclin-dependent kinase inhibitor $1 \mathrm{~A}$ & 4.4 & 0.00015 & $\mathrm{Up}$ \\
\hline NM_001259 & TC07001603.hg.1 & CDK6 & Cyclin-dependent kinase 6 & 4.3 & 0.00013 & $\mathrm{Up}$ \\
\hline NM_001172477 & TC08001496.hg.1 & RRM2B & Ribonucleotide reductase M2 B & 3.7 & 0.00015 & $\mathrm{Up}$ \\
\hline NM_001199933 & TC06001997.hg.1 & SESN1 & Sestrin 1 & 3.6 & 0.00004 & $\mathrm{Up}$ \\
\hline NM_000602 & TC07000643.hg.1 & SERPINE1 & $\begin{array}{l}\text { serpin peptidase inhibitor, clade } \mathrm{E} \\
\text { (nexin, plasminogen activator } \\
\text { inhibitor type } 1 \text { ), member } 1\end{array}$ & 2.2 & 0.00406 & $\mathrm{Up}$ \\
\hline
\end{tabular}


Table IV. Continued.

\begin{tabular}{|c|c|c|c|c|c|c|}
\hline $\begin{array}{l}\text { Pathway/ } \\
\text { Genebank ID }\end{array}$ & Probe_Set_ID & $\begin{array}{l}\text { Gene } \\
\text { symbol }\end{array}$ & $\begin{array}{l}\text { Description of } \\
\text { expression product }\end{array}$ & $\begin{array}{l}\text { Fold } \\
\text { change }\end{array}$ & P-values & $\begin{array}{l}\text { Regulation after } \\
\text { borax treeatment }\end{array}$ \\
\hline NM_004324 & TC19000716.hg.1 & BAX & BCL2-associated X protein & 2.2 & 0.00672 & Up \\
\hline NM_001034 & TC02000057.hg.1 & RRM2 & ribonucleotide reductase $\mathrm{M} 2$ & -2.9 & 0.00010 & Down \\
\hline NM_002639 & TC18000226.hg.1 & SERPINB5 & $\begin{array}{l}\text { Serpin peptidase inhibitor, clade B } \\
\text { (ovalbumin), member } 5\end{array}$ & -2.8 & 0.00756 & Down \\
\hline NM_001196 & TC01000866.hg.1 & BID & $\mathrm{BH} 3$ interacting domain death agonist & -2.5 & 0.00002 & Down \\
\hline NM_016426 & TC22000394.hg.1 & GTSE1 & G-2 and S-phase expressed 1 & -2.4 & 0.00019 & Down \\
\hline NM_003620 & TC17000739.hg.1 & PPM1D & $\begin{array}{l}\text { Protein phosphatase, } \mathrm{Mg} 2+/ \mathrm{Mn} 2+ \\
\text { dependent, } 1 \mathrm{D}\end{array}$ & 4.5 & 0.00005 & Up \\
\hline NM_003842 & TC08001049.hg.1 & TNFRSF10B & $\begin{array}{l}\text { Tumor necrosis factor receptor } \\
\text { superfamily, member } 10 \mathrm{~b}\end{array}$ & 3.8 & 0.00005 & Up \\
\hline NM_031459 & TC01000377.hg.1 & SESN2 & Sestrin 2 & 3.7 & 0.00119 & Up \\
\hline NM_003246 & TC15000270.hg.1 & THBS1 & Thrombospondin 1 & 2.5 & 0.00013 & Up \\
\hline NM_010277 & TC66000070.hg.1 & UBE4B & Ubiquitination factor E4B & -17.44 & 0.00000 & Down \\
\hline NM_005351 & TC62000079.hg.1 & PLOD1 & $\begin{array}{l}\text { Procollagen-lysine, 2-oxoglutarate } \\
\text { 5-dioxygenase } 1\end{array}$ & -16.78 & 0.00104 & Down \\
\hline NM_004701 & TC15000449.hg.1 & CCNB2 & Cyclin B2 & -2.7 & 0.00011 & Down \\
\hline NM_001786 & TC02001182.hg.1 & CDK1 & Cyclin-dependent kinase 1 & -2.5 & 0.00163 & Down \\
\hline NM_057749 & TC08001438.hg.1 & CCNE2 & Cyclin E2 & -2.4 & 0.00622 & Down \\
\hline NM_022470 & TC03002022.hg.1 & ZMAT3 & Zinc finger, matrin-type 3 & -2.2 & 0.00161 & Down \\
\hline
\end{tabular}

hsa04668:TNF signaling pathway

NM_006290 TC06001027.hg.1 TNFAIP3

NM_006941 TC11001948.hg.1 TCF19

NM_001168319 TC06000087.hg.1 EDN1

NM_001145138 TC11001939.hg.1 RELA

NM_001244134 TC10002935.hg.1 MAP3K8

NM_000214 TC20000621.hg.1 JAG1

NM_000963 TC01003638.hg.1 PTGS2

$\begin{array}{lll}\text { NM_001166 } & \text { TC11000957.hg.1 } & \text { BIRC2 } \\ \text { NM_000600 } & \text { TC05001366.hg.1 } & \text { IL6 } \\ \text { NM_182810 } & \text { TC22000317.hg.1 } & \text { ATF4 }\end{array}$

NM-029914 TC61000040.hg.1 UBIAD1

NM_001256045 TC03001824.hg.1 PIK3CB

NM_001065 TC12001135.hg.1 TNFRSF1A

NM_002758 TC17000807.hg.1 MAP2K6

NM_002982 TC17000383.hg.1 CCL2

NM_001114172 TC01002616.hg.1 PIK3R3

NM_005027 TC19002628.hg.1 PIK3R2
Tumor necrosis factor, alpha-induced protein 3

Transcription factor 19

Endothelin 1

V-rel reticuloendotheliosis viral

oncogene homolog A (avian)

Mitogen-activated protein kinase

kinase kinase 8

Jagged 1

Prostaglandin-endoperoxide synthase 2

(prostaglandin $\mathrm{G} / \mathrm{H}$ synthase and

cyclooxygenase)

Baculoviral IAP repeat containing $2 \quad 2.3 \quad 0.00069 \quad$ Up

Interleukin-6

Activating transcription factor 4 (tax-

responsive enhancer element B67)

UbiA prenyltransferase domain

$\begin{array}{ll}-16.88 & 0.00108\end{array}$ containing 1

Phosphoinositide-3-kinase, catalytic, beta polypeptide

Tumor necrosis factor receptor

superfamily, member $1 \mathrm{~A}$

Mitogen-activated protein kinase

kinase 6

Chemokine (C-C motif) ligand 2

Phosphoinositide-3-kinase, regulatory subunit 3 (gamma)

Phosphoinositide-3-kinase, regulatory subunit 2 (beta)
Down

$20.2 \quad 0.00007 \quad \mathrm{Up}$

$\begin{array}{lll}8.96 & 0.00064 \quad U p\end{array}$

$\begin{array}{lll}3.0 & 0.00025 & \mathrm{Up}\end{array}$

$\begin{array}{lll}3.0 & 0.00002 \quad \mathrm{Up}\end{array}$

$2.9 \quad 0.00013 \quad \mathrm{Up}$

$\begin{array}{lll}2.7 & 0.00019 \quad \mathrm{Up}\end{array}$

$\begin{array}{lll}2.6 & 0.02677 \quad \mathrm{Up}\end{array}$

$\begin{array}{lll}2.2 & 0.00002 \quad \mathrm{Up}\end{array}$

$\begin{array}{lll}2.2 & 0.00548 \quad \mathrm{Up}\end{array}$

$0.00108 \quad$ Down

$\begin{array}{ll}-4.7 & 0.00000 \quad \text { Down }\end{array}$

-4.0 $0.00035 \quad$ Down

$-4.0 \quad 0.00021 \quad$ Down

$\begin{array}{ll}-2.6 & 0.03428 \quad \text { Down }\end{array}$

$\begin{array}{ll}-2.3 & 0.00083 \quad \text { Down }\end{array}$

-2.3 $0.00044 \quad$ Down 
Table IV. Continued.

\begin{tabular}{|c|c|c|c|c|c|c|}
\hline $\begin{array}{l}\text { Pathway/ } \\
\text { Genebank ID }\end{array}$ & Probe_Set_ID & $\begin{array}{c}\text { Gene } \\
\text { symbol }\end{array}$ & $\begin{array}{c}\text { Description of } \\
\text { expression product }\end{array}$ & $\begin{array}{c}\text { Fold } \\
\text { change }\end{array}$ & P-values & $\begin{array}{l}\text { Regulation after } \\
\text { borax treeatment }\end{array}$ \\
\hline NM_001136153 & TC06004121.hg.1 & ATF6B & Activating transci & -2.1 & 0.00045 & Down \\
\hline NM_001199427 & TC14000786.hg.1 & TRAF3 & $\begin{array}{l}\text { TNF receptor-associated factor } 3 \\
\text { (TRAF3) }\end{array}$ & -2.1 & 0.00073 & Down \\
\hline
\end{tabular}

hsa04152:AMPK signaling pathway

\begin{tabular}{|c|c|c|c|c|c|c|}
\hline NM_003749 & TC13000871.hg.1 & IRS2 & Insulin receptor substrate 2 & 3.5 & 0.00044 & $\mathrm{Up}$ \\
\hline NM_000875 & TC15000949.hg.1 & IGF1R & Insulin-like growth factor 1 receptor & 3.5 & 0.00188 & $\mathrm{Up}$ \\
\hline NM_181715 & TC01003280.hg.1 & CRTC2 & $\begin{array}{l}\text { CREB regulated transcription } \\
\text { coactivator } 2\end{array}$ & 3.0 & 0.00176 & Up \\
\hline NM_006253 & TC12000936.hg.1 & PRKAB1 & $\begin{array}{l}\text { Protein kinase, AMP-activated, beta } 1 \\
\text { non-catalytic subunit }\end{array}$ & 2.7 & 0.00031 & Up \\
\hline NM_012238 & TC10000400.hg.1 & SIRT1 & Sirtuin 1 & 2.5 & 0.00023 & Up \\
\hline NM_001018053 & TC01001731.hg.1 & PFKFB2 & $\begin{array}{l}\text { 6-phosphofructo-2-kinase/ } \\
\text { fructose-2,6-biphosphatase } 2\end{array}$ & 2.4 & 0.00008 & Up \\
\hline NM_000859 & TC05000363.hg.1 & HMGCR & $\begin{array}{l}\text { 3-hydroxy-3-methylglutaryl-CoA } \\
\text { reductase }\end{array}$ & -4.8 & 0.00001 & Down \\
\hline NM_001256045 & TC03001824.hg.1 & PIK3CB & $\begin{array}{l}\text { Phosphoinositide-3-kinase, catalytic, } \\
\text { beta polypeptide }\end{array}$ & -4.7 & 0.00000 & Down \\
\hline NM_005063 & TC10000721.hg.1 & SCD & $\begin{array}{l}\text { Stearoyl-CoA desaturase } \\
\text { (delta-9-desaturase) }\end{array}$ & -4.6 & 0.00323 & Down \\
\hline NM_001237 & TC04001516.hg.1 & CCNA2 & Cyclin A2 & -3.5 & 0.00007 & Down \\
\hline NM_001199756 & TC01001771.hg.1 & PPP2R5A & $\begin{array}{l}\text { Protein phosphatase } 2 \text {, regulatory } \\
\text { subunit B', alpha }\end{array}$ & -2.8 & 0.00000 & Down \\
\hline NM_004104 & TC17001973.hg.1 & FASN & Fatty acid synthase & -2.6 & 0.00024 & Down \\
\hline NM_198834 & TC17001406.hg.1 & ACACA & Acetyl-CoA carboxylase alpha & -2.6 & 0.00073 & Down \\
\hline NM_005027 & TC19002628.hg.1 & PIK3R2 & $\begin{array}{l}\text { Phosphoinositide-3-kinase, regulatory } \\
\text { subunit } 2\end{array}$ & -2.3 & 0.00044 & Down \\
\hline NM_001114172 & TC01002616.hg.1 & PIK3R3 & $\begin{array}{l}\text { Phosphoinositide-3-kinase, } \\
\text { regulatory subunit } 3 \text { (gamma) }\end{array}$ & -2.3 & 0.00083 & Down \\
\hline NM_005037 & TC03000069.hg.1 & PPARG & $\begin{array}{l}\text { Peroxisome proliferator-activated } \\
\text { receptor gamma }\end{array}$ & -2.1 & 0.00108 & Down \\
\hline NM_001177562 & TC11002284.hg.1 & PPP2R1B & $\begin{array}{l}\text { Protein phosphatase } 2 \text {, regulatory } \\
\text { subunit A }\end{array}$ & -2.0 & 0.01473 & Down \\
\hline
\end{tabular}

hsa04621:NOD-like receptor signaling pathway

\begin{tabular}{|c|c|c|c|c|c|c|}
\hline NM_006290 & TC06001027.hg.1 & TNFAIP3 & $\begin{array}{l}\text { Tumor necrosis factor, alpha-induced } \\
\text { protein } 3\end{array}$ & 20.2 & 0.00007 & Up \\
\hline NM_001562 & TC11002293.hg.1 & IL18 & Interleukin-18 & 3.1 & 0.00033 & Up \\
\hline NM_001145138 & TC11001939.hg.1 & RELA & $\begin{array}{l}\text { V-rel reticuloendotheliosis viral } \\
\text { oncogene homolog A }\end{array}$ & 3.0 & 0.00002 & Up \\
\hline NM_001166 & TC11000957.hg.1 & BIRC2 & Baculoviral IAP repeat containing 2 & 2.3 & 0.00069 & Up \\
\hline NM_004620 & TC11001560.hg.1 & TRAF6 & $\begin{array}{l}\text { TNF receptor-associated factor } 6 \text {, } \\
\text { E3 ubiquitin protein ligase }\end{array}$ & 2.3 & 0.00000 & Up \\
\hline NM_000600 & TC05001366.hg.1 & IL6 & Interleukin-6 & 2.2 & 0.00002 & Up \\
\hline NM_001006600 & TC05000280.hg.1 & ERBB2IP & Erbb2 interacting protein & -3.1 & 0.00030 & Down \\
\hline NM_002982 & TC17000383.hg.1 & CCL2 & Chemokine (C-C motif) ligand 2 & -2.6 & 0.03428 & Down \\
\hline NM_001017963 & TC14001526.hg.1 & HSP90AA1 & $\begin{array}{l}\text { Heat shock protein } 90 \mathrm{kDa} \text { alpha } \\
\text { (cytosolic), class A member } 1\end{array}$ & -2.5 & 0.00029 & Down \\
\hline
\end{tabular}

widely accepted as a p53 upstream target gene, contributes to the migration and invasion of tumor cells $(48,49)$. UBIAD1, also known as UbiA prenyltransferase domain-containing protein 1, functions as an important regulator in the cell progression of bladder and prostate cancer, as well as vascular integrity, possibly through its modulation of metabolism of intracellular 


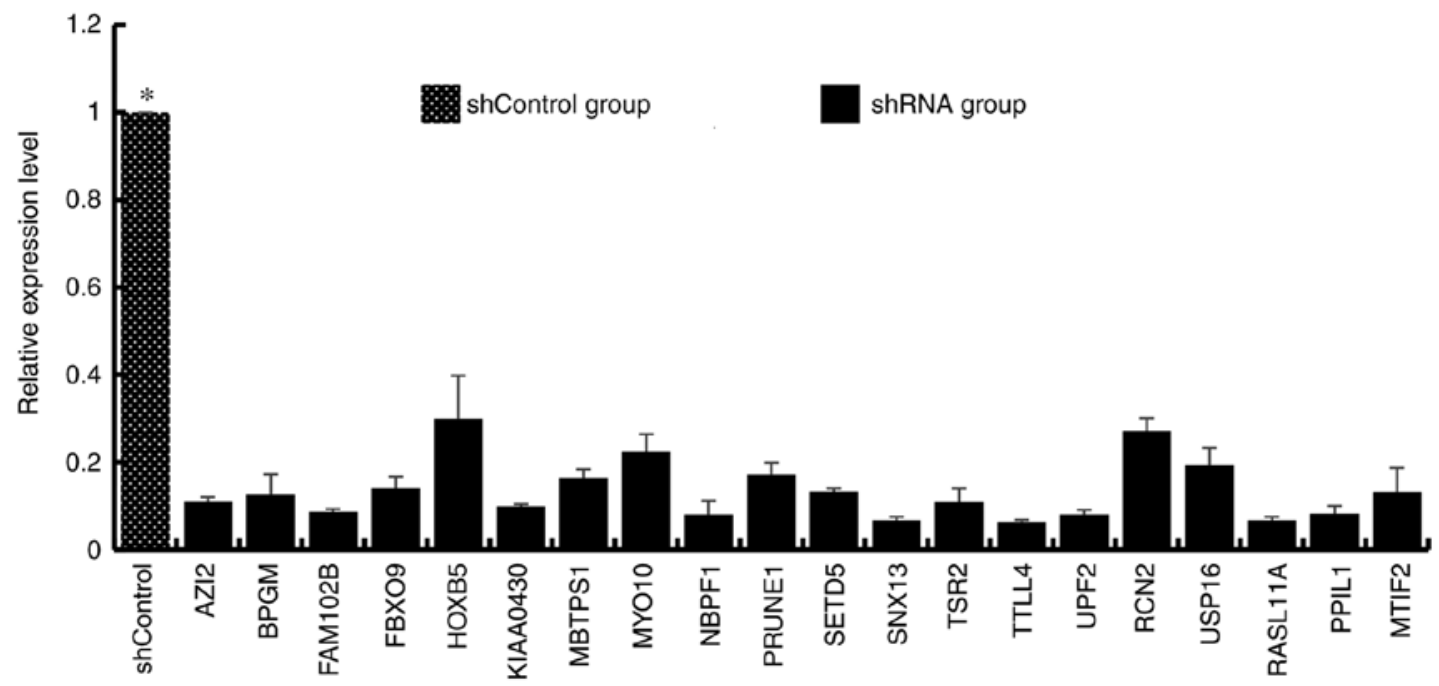

Figure 5. The decreased expression of genes was established following transfection with each shRNA with real-time PCR. "P<0.05, vs. shControl. shRNA, short hairpin RNA.

cholesterol and protection against oxidative stress (50). UBIAD1 was also downregulated. Additionally, PLOD1, which is associated with cell apoptosis, cell cycle and metastasis (51), was also found to be downregulated.

In the present study, 24-h treatment with borax upregulated the expression of several genes, including ZNF84, which is also known as a zinc finger transcription factor gene (52). ZNF84 is located in chromosome 12q24.33, which is correlated with recurrent breakpoints and allelic loss in a few types of cancer $(52,53)$. Immediate early response 3 was another upregulated gene that normally regulates apoptosis, proliferation and the maintenance of HCCs $(54,55)$. TCF19, which was also upregulated, has been identified to be a good prognostic candidate for $\mathrm{HCC}$, thereby becoming a promising candidate for preclinical and/or clinical studies to determine its potential risk in HCCs (56).

Distinct sets of genes were found to be altered after different treatment durations, namely, borax treatments for either 2 or $24 \mathrm{~h}$ in HepG 2 cells. Exposure to borax for $2 \mathrm{~h}$ altered the expression levels of genes encoding proteins involved in signal transduction underlying stress response, biopolymer metabolic process, the inflammatory response (e.g., NF- $\mathrm{BB}$ and caspase--6) and unfolded protein response among other possibilities. Notably, the results for cells from the 2-h treatment group revealed the disruption of certain metabolic processes involved in inflammation and stress response. Accordingly, borax treatment for $24 \mathrm{~h}$ caused the dysregulation of genes involved in a number of signaling pathways, which are associated with enhanced cell proliferation and apoptosis underlying the disruption of both vascular integrity and suppression of tumor cell progression (16), indicating that the disruption of those signaling pathways may contribute to carcinogenesis in borax-treated HepG2 cells.

Enriched GO analyses in the present study revealed that the significantly enriched gene sets included the response to primary metabolic process, response to stimulus, biosynthetic process, developmental process, apoptotic process, immune system process, binding, catalytic activity, cell part, organelles, and others. In the present study, the downregulation of PRUNE1,
NBPF1, PPcaspase-1, UPF2, and MBTPS1 suggested that they inhibited the growth of HepG2 cells. For instance, PRUNE1 is a member of the Asp-His-His phosphoesterase protein superfamily, which is involved in cell motility and is implicated in cancer progression (57). NBPF1 is a tumor suppressor in several cancer types and can act as a tumor suppressor modulating cell apoptosis, possibly through the inhibition of various proteins involved in the cell cycle (58). NBPF1 is also implicated in cancer progression (59). PPcaspase-1 has also been reported to be upregulated in human colon cancer cells. Accordingly, small interfering RNA-mediated PPcaspase-1 knockdown resulted in cell apoptosis in those cells (60). Therefore, precise modulations of the expression level of these critical genes leads to accurate regulation of cellular activity, thereby contributing to the suppressed initiation of cancer progression. Notably, future progress in identifying the basic features of these essential proteins may provide further insights into the diagnosis and prognosis of certain types of human cancer and may also aid the production of novel strategies to develop more effective and efficient therapeutic agents against those types of cancer.

To conclude, 2- and 24-h borax treatment caused significant alterations in the expression levels of various genes. However, based on the length of treatment different sets of genes were altered. Dysregulated genes were identified to be involved in various critical signaling pathways underlying biological processes, including the inflammatory response, stress response, cell apoptosis, signal transduction and cell-to-cell signaling. Some of these changes in those biological processes persisted $24 \mathrm{~h}$ after treatment. Thus, it was demonstrated that borax could induce significant alterations in gene expression. However, further studies are required to determine whether these changes are ascribed to genetic alterations in the promoter or regulatory regions of dysregulated genes. Notably, these studies could bring further insights into how borax affects gene expression. The present study provides the fundamental basis for exploring the carcinogenicity of borax treatment in HepG2 to reveal the underlying cellular and molecular mechanisms, the basic 



Figure 6. HepG2 cells were transfected with RNAiMax and counts of live adherent HepG2 in cell culture using a Celigo cytometer at the time points indicated (A) GFP expression of cells infected with different AdGFP-iRNA. (B) Graphs indicated the number of viable cells. (C) Graphs indicated cell growth according to fold change [fold change $=$ shControl/experimental group (transfected with RNAiMax) $\geq 1.5, \mathrm{P}<0.05$ ]. Ctrl, non-targeting shRNA, PC, positive control (specific-targeting shRNA); AdGFP, adenoviral green fluorescent protein. 
biological characteristics and associated pathways, which warrant further investigation.

\section{Acknowledgements}

Not applicable.

\section{Funding}

This work was funded by the National Natural Scientific Foundation of China (grant no. 81872509), the Natural Science Foundation of Hubei Provincial Department of Education (grant no. D20172101), the Hubei Provincial Technology Innovation Project (grant no. 2017ACA176), the Hubei Province Health and Family Planning Scientific Research Project (grant no. WJ2019M054), the Natural Science Foundation of Hubei Provincial Department of Education (grant no. Q20162113) and the Natural Science Foundation of the Bureau of Science and Technology of Shiyan City (grant no. 18Y76, 17Y47).

\section{Availability of data and materials}

The datasets used and/or analyzed during the current study are available from the corresponding author on reasonable request.

\section{Authors' contributions}

LW, YW, ZGT and YSZ conceived and designed the experiments. LW,ZPZ, JZ, HMW, GMW and SW contributed reagents, materials and analysis tools and performed the experiments. LW, WBZ, QHC, LHY and MXL analyzed and interpreted the experimental data. LW was a major contributor in writing the manuscript. All authors read and approved the final manuscript.

\section{Ethics approval and consent to participate}

Not applicable.

\section{Patient consent for publication}

Not applicable.

\section{Competing interests}

The authors declare that they have no competing interests.

\section{References}

1. Routray I and Ali S: Boron induces lymphocyte proliferation and modulates the priming effects of lipopolysaccharide on macrophages. PLoS One 11: e0150607, 2016.

2. Neiner D, Sevryugina YV, Harrower LS and Schubert DM Structure and properties of sodium enneaborate $\mathrm{Na}_{2}\left[\mathrm{~B}_{8} \mathrm{O}_{11}(\mathrm{OH})_{4}\right] \cdot \mathrm{B}(\mathrm{OH})_{3} \cdot 2 \mathrm{H}_{2} \mathrm{O}$. Inorg Chem 56: 7175-7181, 2017.

3. Alak G, Parlak V, Yeltekin AÇ, Ucar A, Çomaklı S, Topal A, Atamanalp M, Özkaraca M and Türkez $\mathrm{H}$ : The protective effect exerted by dietary borax on toxicity metabolism in rainbow trout (Oncorhynchus mykiss) tissues. Comp Biochem Physiol C Toxicol Pharmacol 216: 82-92, 2019.

4. Alak G, Parlak V, Aslan ME, Ucar A, Atamanalp M and Turkez H: Borax supplementation alleviates hematotoxicity and DNA damage in rainbow trout (Oncorhynchus mykiss) exposed to copper. Biol Trace Elem Res 187: 536-542: 2019.
5. Hussain SA, Abood SJ and Gorial FI: The adjuvant use of calcium fructoborate and borax with etanercept in patients with rheumatoid arthritis: Pilot study. J Intercult Ethnopharmacol 6: 58-64, 2016.

6. Ince S, Kucukkurt I, Cigerci IH, Fatih Fidan A and Eryavuz A: The effects of dietary boric acid and borax supplementation on lipid peroxidation, antioxidant activity, and DNA damage in rats. J Trace Elem Med Biol 24: 161-164, 2010.

7. Sandeep Varma R, Shamsia S, Thiyagarajan OS, Vidyashankar S and Patki PS: Yashada bhasma (Zinc calx) and Tankana (Borax) inhibit Propionibacterium acne and suppresses acne induced inflammation in vitro. Int J Cosmet Sci 36: 361-368, 2014.

8. López-Cabrera Y, Castillo-García EL, Altamirano-Espino JA, Pérez-Capistran T, Farfán-García ED, Trujillo-Ferrara JG and Soriano-Ursúa MA: Profile of three boron-containing compounds on the body weight, metabolism and inflammatory markers of diabetic rats. J Trace Elem Med Biol 50: 424-429, 2018.

9. Geyikoglu F and Turkez H: Boron compounds reduce vanadium tetraoxide genotoxicity in human lymphocytes. Environ Toxicol Pharmacol 26: 342-347, 2008.

10. Gülsoy N, Yavas C and Mutlu Ö: Genotoxic effects of boric acid and borax in zebrafish, Danio rerio using alkaline comet assay. EXCLI J 14: 890-899, 2015.

11. Sarkar PK, Prajapati PK, Shukla VJ and Ravishankar B: Evaluation of processed borax as antidote for aconite poisoning. J Ethnopharmacol 205: 138-146, 2017.

12. Capkin E, Ozcelep T, Kayis S and Altinok I: Antimicrobial agents, triclosan, chloroxylenol, methylisothiazolinone and borax, used in cleaning had genotoxic and histopathologic effects on rainbow trout. Chemosphere 182: 720-729, 2017.

13. Pongsavee M: Genotoxic effects of borax on cultured lymphocytes. Southeast Asian J Trop Med Public Health 40: 411-418, 2009.

14. Pongsavee M: Effect of borax on immune cell proliferation and sister chromatid exchange in human chromosomes. J Occup Med Toxicol 4: 27, 2009.

15. Çelikezen FÇ, Toğar B, Özgeriş FB, İzgi MS and Türkez H: Cytogenetic and oxidative alterations after exposure of cultured human whole blood cells to lithium metaborate dehydrate. Cytotechnology 68: 821-827, 2016.

16. Wei Y, Yuan FJ, Zhou WB, Wu L, Chen L, Wang JJ and Zhang YS: Borax-induced apoptosis in HepG2 cells involves p53, Bcl-2, and Bax. Genet Mol Res 15, 2016.

17. Brocato J and Costa M: Basic mechanics of DNA methylation and the unique landscape of the DNA methylome in metal-induced carcinogenesis. Crit Rev Toxicol 43: 493-514, 2013.

18. Hazman Ö, Bozkurt MF, Fidan AF, Uysal FE and Çelik S: the effect of boric acid and borax on oxidative stress, inflammation, ER stress and apoptosis in cisplatin toxication and nephrotoxicity developing as a result of toxication. Inflammation 41: 1032-1048, 2018.

19. Oh SH and Lim SC: A rapid and transient ROS generation by cadmium triggers apoptosis via caspase-dependent pathway in HepG2 cells and this is inhibited through $\mathrm{N}$-acetylcysteine-mediated catalase upregulation. Toxicol Appl Pharmacol 212: 212-223, 2006.

20. Cartularo L, Laulicht F, Sun H, Kluz T, Freedman JH and Costa M: Gene expression and pathway analysis of human hepatocellular carcinoma cells treated with cadmium. Toxicol Appl Pharmacol 288: 399-408, 2015.

21. Livak KJ and Schmittgen TD: Analysis of relative gene expression data using real-time quantitative PCR and the 2(-Delta Delta C(T)) method. Methods 25: 402-408, 2001.

22. Zhang DY, Liu Z, Lu Z, Sun WL, Ma X, Zhang P, Wu BQ and Cui PY: Lentivirus-mediated overexpression of HSDL2 suppresses cell proliferation and induces apoptosis in cholangiocarcinoma. Onco Targets Ther 11: 7133-7142, 2018.

23. Zheng J, You W, Zheng C, Wan P, Chen J, Jiang X, Zhu Z, Zhang Z, Gong A, Li W, et al: Knockdown of FBXO39 inhibits proliferation and promotes apoptosis of human osteosarcoma U-2OS cells. Oncol Lett 16: 1849-1854, 2018.

24. Yamada KE and Eckhert CD: Boric acid activation of eIF $2 \alpha$ and Nrf2 Is PERK dependent: A mechanism that explains how boron prevents DNA damage and enhances antioxidant status. Biol Trace Elem Res 188: 2-10, 2019.

25. Matencio A, Navarro-Orcajada S, García-Carmona F and López-Nicolás JM: Ellagic acid-borax fluorescence interaction: Application for novel cyclodextrin-borax nanosensors for analyzing ellagic acid in food samples. Food Funct 9: 3683-3687, 2018. 
26. Donoiu I, Militaru C, Obleagă O, Hunter JM, Neamţu J, Biţă A, Scorei IR and Rogoveanu OC: Effects of boron-containing compounds on cardiovascular disease risk factors-a review. J Trace Elem Med Biol 50: 47-56, 2018.

27. Worm DJ, Els-Heindl S, Kellert M, Kuhnert R, Saretz S, Koebberling J, Riedl B, Hey-Hawkins E and Beck-Sickinger AG: A stable meta-carborane enables the generation of boron-rich peptide agonists targeting the ghrelin receptor. J Pept Sci 24: e3119, 2018.

28. Rico P, Rodrigo-Navarro A and Salmerón-Sánchez M Borax-Loaded PLLA for promotion of myogenic differentiation. Tissue Eng Part A 21: 2662-2672, 2015.

29. Das BC, Thapa P, Karki R, Schinke C, Das S, Kambhampati S, Banerjee SK, Van Veldhuizen P, Verma A, Weiss LM and Evans T: Boron chemicals in diagnosis and therapeutics. Future Med Chem 5: 653-676, 2013

30. Turkez H: Effects of boric acid and borax on titanium dioxide genotoxicity. J Appl Toxicol 28: 658-664, 2008.

31. Jensen JP: The rise and fall of borax as an antiepileptic drug. Arch Neurol 63: 621-622, 2006.

32. Meyer-Hamme G, Beckmann K, Radtke J, Efferth T, Greten HJ, Rostock M and Schröder S: A survey of chinese medicinal herbal treatment for chemotherapy-induced oral mucositis. Evid Based Complement Alternat Med 2013: 284959, 2013.

33. Landolph JR: Cytotoxicity and negligible genotoxicity of borax and borax ores to cultured mammalian cells. Am J Ind Med 7: 31-43, 1985.

34. Chen CP, Sun ZL, Lu X, Wu WX, Guo WL, Lu JJ, Han C, Huang JQ and Fang Y: MiR-340 suppresses cell migration and invasion by targeting MYO10 in breast cancer. Oncol Rep 35: 709-716, 2016.

35. Makowska KA, Hughes RE, White KJ, Wells CM and Peckham M: Specific myosins control actin organization, cell morphology, and migration in prostate cancer cells. Cell Rep 13: $2118-2125,2015$

36. Zhang H, He P, Huang R, Sun L, Liu S, Zhou J, Guo Y, Yang D and Xie P: Identification and bioinformatic analysis of dysregulated microRNAs in human oligodendroglial cells infected with borna disease virus. Mol Med Rep 14: 4715-4722, 2016.

37. Pinto JA, Rolfo C, Raez LE, Prado A, Araujo JM, Bravo L, Fajardo W, Morante ZD, Aguilar A, Neciosup SP, et al: In silico evaluation of DNA Damage Inducible Transcript 4 gene (DDIT4) as prognostic biomarker in several malignancies. Sci Rep 7: 1526, 2017.

38. Shatov VM, Weeks SD, Strelkov SV and Gusev NB: The role of the arginine in the conserved $\mathrm{N}$-terminal domain RLFDQxFG motif of human small heat shock proteins HspB1, HspB4, HspB5, HspB6, and HspB8. Int J Mol Sci 19: pii: E2112, 2018.

39. Konda JD, Olivero M, Musiani D, Lamba S and Di Renzo MF: Heat-shock protein 27 (HSP27, HSPB1) is synthetic lethal to cells with oncogenic activation of MET, EGFR and BRAF. Mol Oncol 11: 599-611, 2017.

40. Mohamad T, Kazim N, Adhikari A and Davie JK: EGR1 interacts with TBX2 and functions as a tumor suppressor in rhabdomyosarcoma. Oncotarget 9: 18084-18098, 2018.

41. Li H, Wang J, Liu X and Cheng Q: MicroRNA-204-5p suppresses caspase-6-mediated inflammatory response and chemokine generation in HK-2 renal tubular epithelial cells by targeting caspase-6R. Biochem Cell Biol 97: 109-117, 2019.

42. Zhai Y, Lin P, Feng Z, Lu H, Han Q, Chen J, Zhang Y, He Q, Nan G, Luo X, et al: TNFAIP3-DEPTOR complex regulates inflammasome secretion through autophagy in ankylosing spondylitis monocytes. Autophagy 14: 1629-1643, 2018.

43. Pinna F, Bissinger M, Beuke K, Huber N, Longerich T, Kummer U, Schirmacher P, Sahle S and Breuhahn K: A20/TNFAIP3 discriminates tumor necrosis factor (TNF)-Induced NF- $\kappa \mathrm{B}$ from JNK pathway activation in hepatocytes. Front Physiol 8: 610, 2017.

44. Wen J, Xiao J, Rahdar M, Choudhury BP, Cui J, Taylor GS Esko JD and Dixon JE: Xylose phosphorylation functions as a molecular switch to regulate proteoglycan biosynthesis. Proc Natl Acad Sci USA 111: 15723-15728, 2014.
45. Taylan F and Mäkitie O: Abnormal proteoglycan synthesis due to gene defects causes skeletal diseases with overlapping phenotypes. Horm Metab Res 48: 745-754, 2016.

46. Van Damme T, Pang X, Guillemyn B, Gulberti S, Syx D, De Rycke R, Kaye O, de Die-Smulders CEM, Pfundt R, Kariminejad A, et al: Biallelic B3GALT6 mutations cause spondylodysplastic Ehlers-Danlos syndrome. Hum Mol Genet 27: 3475-3487, 2018

47. Zhang XF, Pan QZ, Pan K, Weng DS, Wang QJ, Zhao JJ, He J, Liu Q, Wang DD, Jiang SS, et al: Expression and prognostic role of ubiquitination factor E4B in primary hepatocellular carcinoma. Mol Carcinog 55: 64-76, 2016.

48. Periz G, Lu J, Zhang T, Kankel MW, Jablonski AM, Kalb R, McCampbell A and Wang J: Regulation of protein quality control by UBE4B and LSD1 through p53-mediated transcription. PLoS Biol 13: e1002114, 2015.

49. Wang B, Wu H, Chai C, Lewis J, Pichiorri F, Eisenstat DD, Pomeroy SL and Leng RP: MicroRNA-1301 suppresses tumor cell migration and invasion by targeting the $\mathrm{p53} / \mathrm{UBE} 4 \mathrm{~B}$ pathway in multiple human cancer cells. Cancer Lett 401: 20-32, 2017.

50. Okano T: A new horizon in vitamin $\mathrm{K}$ research. Yakugaku Zasshi 136: 1141-1159, 2016 (In Japanese).

51. Li L, Wang W, Li X and Gao T: Association of ECRG4 with PLK1, CDK4, PLOD1 and PLOD2 in esophageal squamous cell carcinoma. Am J Transl Res 9: 3741-3748, 2017.

52. Rosati M, Rocchi M, Storlazzi CT and Grimaldi G: Assignment to chromosome $12 \mathrm{q} 24.33$, gene organization and splicing of the human KRAB/FPB containing zinc finger gene ZNF84. Cytogenet Cell Genet 94: 127-130, 2001

53. Assou S, Cerecedo D, Tondeur S, Pantesco V, Hovatta O, Klein B Hamamah S and De Vos J: A gene expression signature shared by human mature oocytes and embryonic stem cells. BMC Genomics 10: 10, 2009.

54. Zhou Q, Hahn JK, Neupane B, Aidery P, Labeit S, Gawaz M and Gramlich M: Dysregulated ier3 expression is associated with enhanced apoptosis in titin-based dilated cardiomyopathy. Int J Mol Sci 18: pii: E723, 2017.

55. Tran DDH, Koch A, Allister A, Saran S, Ewald F, Koch M, Nashan B and Tamura T: Treatment with MAPKAP2 (MK2) inhibitor and DNA methylation inhibitor, 5-aza dC, synergistically triggers apoptosis in hepatocellular carcinoma (HCC) via tristetraprolin (TTP). Cell Signal 28: 1872-1880, 2016.

56. Mathew S, Abdel-Hafiz H, Raza A, Fatima K and Qadri I: Host nucleotide polymorphism in hepatitis B virus-associated hepatocellular carcinoma. World J Hepatol 8: 485-498, 2016.

57. Zollo M, Ahmed M, Ferrucci V, Salpietro V, Asadzadeh F, Carotenuto M, Maroofian R, Al-Amri A, Singh R, Scognamiglio I, et al: PRUNE is crucial for normal brain development and mutated in microcephaly with neurodevelopmental impairment. Brain 140: 940-952, 2017.

58. Li D, Li P, Wu J, Yi J, Dou Y, Guo X, Yin Y, Wang D, Ma C and Qiu L: Methylation of NBPF1 as a novel marker for the detection of plasma cell-free DNA of breast cancer patients. Clin Chim Acta 484: 81-86, 2018

59. Andries V, Vandepoele K, Staes K, Berx G, Bogaert P, Van Isterdael G, Ginneberge D, Parthoens E, Vandenbussche J, Gevaert K and van Roy F: NBPF1, a tumor suppressor candidate in neuroblastoma, exerts growth inhibitory effects by inducing a G1 cell cycle arrest. BMC Cancer 15: 391, 2015.

60. Stegmann CM, Lührmann R and Wahl MC: The crystal structure of PPcaspase-1 bound to cyclosporine A suggests a binding mode for a linear epitope of the SKIP protein. PLoS One 5: e10013, 2010 .

This work is licensed under a Creative Commons Attribution-NonCommercial-NoDerivatives 4.0 International (CC BY-NC-ND 4.0) License. 